\title{
Improved manufacture of hybrid membranes with bionanopore adapters capable of self-luting
}

1 Klara Altintoprak Dr. rer. nat

Research Assistant, Department of Molecular Biology and Plant Virology, Institute of Biomaterials and Biomolecular Systems, University of Stuttgart, Stuttgart, Germany

2 Farid Farajollahi Dr. rer. nat. Research Assistant, Institute of Functional Interfaces, Karlsruhe Institute of Technology, Eggenstein-Leopoldshafen, Germany

3 Axel Seidenstücker Dr. rer. nat.

Research Assistant, Institute of Solid State Physics, University of UIm, Ulm, Germany

4 Timo Ullrich BSC

MSc graduate student, Department of Molecular Biology and Plant Virology, Institute of Biomaterials and Biomolecular Systems, University of Stuttgart, Stuttgart, Germany

5 Nana L. Wenz MSc

$\mathrm{PhD/Dr}$. rer. nat. candidate, Department of Molecular Biology and Plant Virology, Institute of Biomaterials and Biomolecular Systems, University of Stuttgart, Stuttgart, Germany

6 Peter Krolla Dipl.-Biol. Research Assistant, Institute of Functional Interfaces, Karlsruhe Institute of Technology, Eggenstein-Leopoldshafen, Germany

7 Alfred Plettl Dr. rer. nat.

Group Leader, Institute of Solid State Physics, University of UIm, UIm, Germany

8 Paul Ziemann Dr. rer. nat. Professor Emeritus, Institute of Solid State Physics, University of Ulm, Ulm, Germany
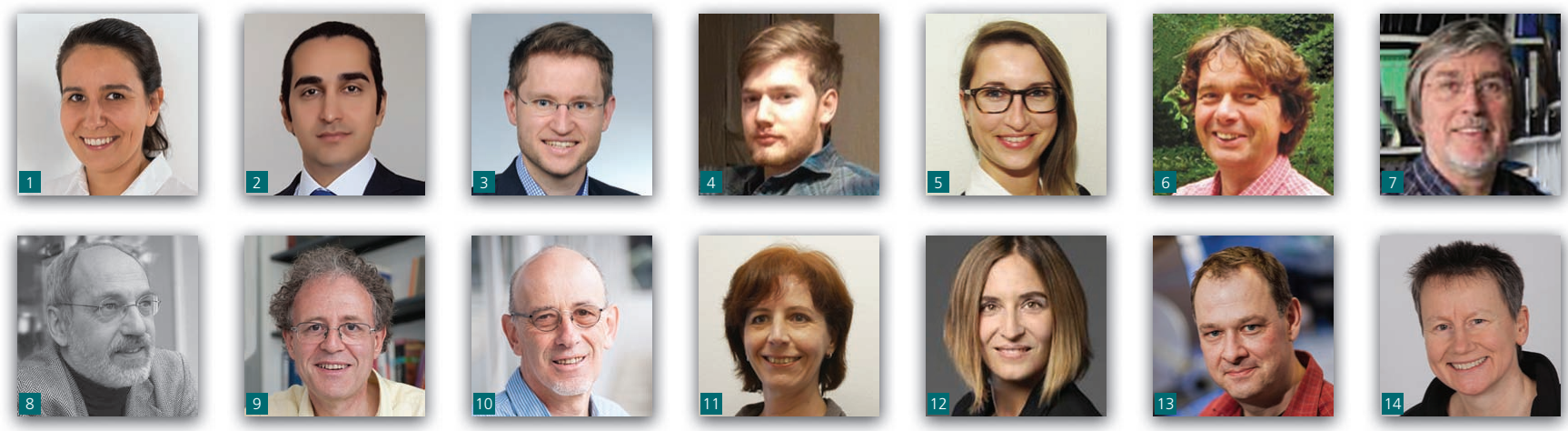

The authors' recent concept of bioinorganic filtration devices made up of solid-state membranes (SSMs) accommodating ring-shaped, ribonucleic acid (RNA)-stabilized tobacco mosaic virus (TMV) coat protein (CP) assemblies with central $4 \mathrm{~nm}$ holes as genetically encoded 'pore-in-pore' fittings, to convey size and charge specificity to the membranes' permeability, has been elaborated. Key developments for simplifying and finishing the unique combination apply to both soft- and hard-matter components: previous SSMs with millions of conical pores demanded sophisticated lithography to achieve a taper trapping the bionanopores upon insertion in a flow. Now focused helium (He) ion beam technology has enabled efficient, fast preparation of silicon nitride templates adapted to the nanorings. Proof-of-concept experiments reveal that negative charges imparted by nucleic acids exposed on the bionanopores might improve electrophoretic implantation further. Suitable peptides installed on the outer nanoring rim had been shown to nucleate spatially confined silica deposition from liquid precursors, which have been optimized in order to seal the annular gaps between bio and inorganic SSM pores by 'bionic glue'. Finally, two engineered CP variants and a modified scaffold RNA were established for novel TMV nanoring types with altered pore charges, which also allow installing accessory molecules for advanced filtration and conversion tasks. 


\author{
Notation \\ $a, b \quad$ correlation constants \\ D ion dose \\ d pore diameter \\ $g$ earth's gravitational acceleration \\ I current \\ $t$ exposure time \\ $V \quad$ voltage
}

\section{Introduction}

The functional capacities of many types of biomolecular nanopores are attracting great interest in viable concepts for their stable integration into technical devices (as recently reviewed ${ }^{1,2-4}$ ). They not only may render size and charge selectivity up to specific molecular recognition for analyte detection and enrichment, but can also even mediate active transport, sequence readout and enzymatic conversion reactions if suitable proteins and/or nucleic acids are incorporated into the pores' architecture. Most biological pores and channels, however, have evolved for tasks within the environment of cellular phospholipid bilayer membranes, which creates major challenges in the design of durable biohybrid components exploiting the capabilities of the biogenic building blocks. For this reason, strategies for either supporting lipid membranes by long-term stable layers or replacing them by a synthetic, but functionally compatible, environment are investigated to an increasing extent. ${ }^{1,4}$ The authors have recently introduced a substantially different and, to their knowledge, so far unique approach that may lead to exceptionally robust and tailorable protein nanopore arrays firmly inserted in inorganic templates: the combination of freestanding solid-state membranes (SSMs) with a multitude of open pores $^{5}$ and precisely shaped, ribonucleic acid (RNA)-stabilized tobacco mosaic virus (TMV) coat protein (CP) nanorings with $4 \mathrm{~nm}$ central holes (perforated 'disks' of more than $65 \mathrm{CPs}, 18 \mathrm{~nm}$ dia. and about $10 \mathrm{~nm}$ thick $^{6}$ ) acting as 'pore-in-pore' fittings, ${ }^{7}$ which provide the opportunity to modulate the central nanopores' size and functionality (see later). For an irreversible interconnection of both the hard- and soft-matter partner components, a biologically inspired, peptide-guided self-luting process was suggested to achieve spatially selective gap sealing through silica deposition in between the nanoring rims and the inorganic SSM templates. The layout of the proposed biohybrid filtration membrane is depicted in Figure 1.

The nanoporous, disk-shaped TMV derivatives have been developed in the authors' team in the past few years and are expected to sustain significant modifications of both their inner and their outer surfaces as concluded from the authors' own ${ }^{6,8-14}$ and others, ${ }^{15-19}$ studies on alterations achieved for TMV CP, without abolishing its assembly competence into higher-order structures. They tolerate an inclusion of different $\mathrm{CP}$ types into a single nanoring and chemical coupling of reactive molecules to selectively addressable functional groups. ${ }^{6,20}$ This makes the nanorings advantageous candidates for the desired bionanopore inlays. To this end, they need to be efficiently combined with the

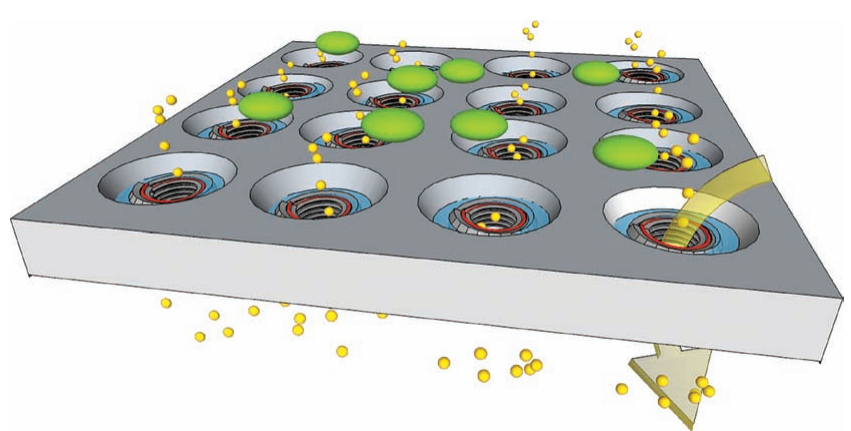

Figure 1. Layout of a novel type of selectively permeable bio/inorganic hybrid membranes enabling molecular sorting by size exclusion and charge-selective passage through protein nanopores. After TMV pore adapter integration (red/white nucleoprotein nanorings) into an inorganic SSM template with conical pores (gray) and gap sealing by 'bionic silica glue' (blue), selective filtration tasks may be realized with respect to molecule sizes and charges (green/yellow analytes), in interdependence with the type of the implanted 'viropore'

hard-matter 'partner template', which in the originally suggested layout consisted of SSMs with millions of identical pore channels. $^{5,21}$ Produced by an elaborate series of distinct lithography techniques, their conical shape trapped the nanoporous disks inside upon diffusive or electrophoretic insertion. ${ }^{7}$ Here, the authors present key advancements for easing, functionally finishing and characterizing the fabrication of such bionanopore arrays in a novel type of membrane backbone: commercial silicon nitride $\left(\mathrm{Si}_{3} \mathrm{~N}_{4}\right.$, 'SN') templates were 'punched' efficiently and reliably by focused helium $(\mathrm{He})$ ion beam technology ${ }^{22}$ to generate holes that fit the TMV-based nanorings, as analyzed by atomic force microscopy (AFM) and electron microscopy techniques described in Section 2.4. In proof-ofprinciple experiments, the authors investigated whether additional negative charges of nucleic acids exposed on the TMV pore-inpore inlays might improve their electrophoretic insertion. Mineralization-inducing peptides ${ }^{8}$ installed on the outer rim of the bionanopore fittings ${ }^{20}$ had been shown by the authors to nucleate silica deposition from suitable liquid precursors. ${ }^{8,20,23}$ This method has now been optimized further to provide all prerequisites for sealing the annular gaps between the nanorings and the inorganic SSM pores by a 'bionic glue' - that is, an irreversibly deposited silica interlayer preventing leakage. Last, but not least, components for new types of TMV-based nanopore inlays were generated, by engineering two new TMV CP variants accessible from TMV multiplied in plants and by $5^{\prime}$-modified scaffold RNAs produced in vitro, shown to guide nanoring assembly efficiently. All of the three nanoring modifications modulate the biopores' charge and allow installing molecules inside or in close vicinity to the central hole. This may enable advanced filtration and even molecular transformation tasks by way of hybrid membranes accommodating the novel TMV-based pore-in-pore fittings. 
To explicate the context of this study, some cornerstones of the tailor-made building blocks and of initial layouts of the biohybrid nanopore arrays previously realized in the authors' team, as well as fundamentals of the underlying methods, are outlined in the following. During recent years, research on ultrathin nanoporous SSMs and the development of preparation techniques for different materials including graphene, oxides, nitrides and polymers have experienced substantial progress. ${ }^{24,25}$ For a parallelized highefficiency production of nanoporous SSMs, bottom-up preparation techniques are frequently used, where, for example, the micelle-based ordered deposition of gold $(\mathrm{Au})$ nanoparticles $(\text { GNPs })^{26-28}$ with controlled size and defined interparticulate distance is combined with reactive ion etching techniques. ${ }^{5,29}$ Although such methods can be used to prepare large-area SSMs, an exact control of both size and shape of the pores is difficult to achieve due to the high number of preparation steps. In contrast to bottom-up procedures, the development of top-down techniques for nanomachining of solids or 'nanodrilling' such as focused ion beam (FIB) or electron beam (e-beam) lithography techniques has opened a wide field of applications, particularly for the preparation of nanopores with defined geometries ${ }^{30}$ and for different materials including conducting, semiconducting or insulating material types. ${ }^{31-33}$ By means of subsequent chemical modifications and surface coatings, refined functionality can be introduced into the pores or channels, up to stimuli-responsive molecules that can even endow reversible gating and selective recognition capacities. ${ }^{34}$ Combinations with biologically evolved macromolecular functions, however, still enable the most complex and fine-tunable nanopore applications, for which reason strategies enabling the formation of stabilized biohybrid layouts are matter of intense research. ${ }^{1-4,35}$

For the preparation of nanoporous membranes, e-beams of a transmission electron microscope (TEM) or scanning electron microscope (SEM) can be used for silicon $(\mathrm{Si})$ or free-standing silicon oxide $\left(\mathrm{SiO}_{2}\right)$ or SN layers, ${ }^{36-38}$ respectively. Recently, the preparation of single pores in graphene membranes by e-beam lithography has been reported..$^{39,40}$ As an example for FIB application, Li et al. ${ }^{41}$ produced individual pores through the exposure of a free-standing SN membrane with argon ion beams. Depending on the experimental conditions, the pore diameters can vary between a few nanometers and several hundreds of nanometers. ${ }^{41}$ As the FIB and e-beam techniques are one-step processes, where the substrate is decomposed directly by the exposure to ions or electrons, tight control of the irradiation dose and - by that - of the material degradation is possible. This allows for precisely defining the lateral size, depth and shape of the pores. In this context, the work of Gierak et al. ${ }^{42}$ who were able to drill sub-5 $\mathrm{nm}$ pores into a silicon carbide substrate, can be seen as a benchmark. While FIBs are usually operated with gallium ions, the helium ion microscope (HIM) represents a highly sophisticated further development of the FIB technique, as helium ions allow for a higher precision in terms of the shape and the distribution of the pore diameters than a conventional FIB. This was demonstrated in 2011 by Yang et al., ${ }^{43}$ who drilled pores with diameters $<5 \mathrm{~nm}$ in solid-state substrates, which were then used for biomolecular detection. Further advantages of the HIM technique, compared to a classical gallium (Ga) ion-based FIB, are $(a)$ that no ion implantation takes place and $(b)$ that the HIM offers an option for direct thinning of membrane sections. ${ }^{44}$ In contrast to artificially prepared inorganic SSM pores, biology offers a huge set of complex and diverse pores, specified and perfectly tailored, for example, for physiological processes. While numerous biological nanopore setups prove their interdisciplinary abilities, for instance, for biosensing applications, ${ }^{1,45}$ the new preparation techniques mentioned earlier enable the SSM section to enter the nanometer and submicrometer scales with precisely defined pore characteristics. ${ }^{38,46}$ Combining the benefits of ultrathin SSMs, such as mechanical and chemical stability, and those of biological protein channel assemblies, such as their controlled positioning by functionalization and the option of channel size and charge modification, bioinorganic hybrid membranes may eventually provide access to further improved and novel applications. ${ }^{1-4,47}$ In the focus of current investigations are filtering and separation processes for specific molecules and ions ${ }^{48-53}$ and applications in the field of deoxyribonucleic acid (DNA) sequencing. ${ }^{54,55}$ Whereas the separation mechanisms of microscopic sieves are mainly based on the special size ratio between the sieve's cross-sectional pore diameter and the corresponding particle size, blocking and transport effects of meso- and nano-scopic pores were observed to be more complex and show a significantly different behavior. ${ }^{56,57}$ Besides the influence of pore geometry, ${ }^{58-60}$ new effects occur such as ionic and molecular selectivity, ${ }^{39,61-67}$ ion current rectification ${ }^{68-71}$ and non-linear (diode) current/voltage behavior. ${ }^{72-74}$ Furthermore, ionic concentrations within the pores were found to differ often from the corresponding bulk solution values. ${ }^{75}$

In a recent work, ${ }^{7}$ the authors demonstrated the proof-of-concept assembly of a biohybrid pore-in-pore membrane, where the previously introduced nanorings of TMV CPs scaffolded by a short RNA were inserted into conical pores of an SSM. As the SSM with millions of nearby pores was prepared by a micellebased colloidal mask technique, the interporous distances could not be controlled tightly and could not be substantially increased or arranged into predefined patterns of choice. In addition, subsequent adjustment of the pores' size and wall taper by top-down techniques with several consecutive steps (e.g. the described micelle-based pore preparation) needs extensive experience to yield reproducible pore dimensions. Therefore, the authors have developed a process for SSM pore preparation by a straightforward HIM-based beam technology. Thereby, it has become possible to create pore arrays in SN substrates with nanometrically defined pore inlet and outlet diameters, exact interporous distances and spatial arrangements adapted to subsequent analytical procedures. The negatively charged nanorings were then successfully inserted into the pores in an electrophoretic setup, in analogy to the authors' previous study, as shown later. Since a large proportion of the disks, however, did not target the pore channels, the authors wanted to find out 
whether or not increased negative charges of the nanoobjects might provide a chance to enhance implantation efficiency. The TMV-deduced nanorings consist of an RNA molecule 204 nucleotides (nt) long, containing the TMV origin-of-assembly (OA) sequence, fully encapsidated into a four-turn helix of about $68 \mathrm{CP}$ subunits that is thereby stabilized against dissociation (as occurring with RNA-free natural TMV CP nanoring structures) and $\mathrm{pH}$-dependent disassembly. ${ }^{6}$ Both RNA and $\mathrm{CP}$ contribute to the moderately negative overall charge of the nanorings. Their nucleoprotein structure, however, offers further possibilities to increase its negative charge - for example, by coupling oligonucleotide strands to its CP or RNA components. The authors therefore sought to test whether DNA-fashioned model particles might undergo an even more efficient insertion into the SSM templates than particles devoid of exposed nucleic acids. Such experiments might help delimit the best integration methods for the bio into the inorganic components, to render hybrid membrane fabrication as cost and labor effective as possible. Oligonucleotidecoated gold nanobeads $20 \mathrm{~nm}$ dia. were used for this purpose and revealed further insights into the implantation process.

After entering the inorganic nanopores, the biomolecular rings need to be immobilized irreversibly to avoid losses through diffusion. An intriguing option for inducing a self-luting process on demand lies in the bioinspired, peptide-guided deposition of silica sheaths around the outer ring rims, to serve as bionic glue between the protein surface and the SSM pore wall. Not only would this approach fix the pore-in-pore inlays inside the template with the help of liquid silica precursors, it should also generate firm sealrings closing the annular gaps around the protein nanorings, blocking these leakage pathways. All prerequisites for a successful application of this in situ self-sealing strategy seemed satisfied due to the authors' previous work, ${ }^{20}$ but needed delicate optimization of the externally induced silicification process, as presented later. Generally, the bioinspired mineralization of selectively functionalized templates is a subject of intense research and goes along with the rapidly growing experience in controlled tooth and bone regeneration, ${ }^{76-81}$ tissue engineering and array applications relying on functionally patterned substrate surfaces, ${ }^{82-84}$ the production of nanoelectronic devices ${ }^{85}$ and drug-delivery vehicles ${ }^{86}$ or the development of selfhealing materials, ${ }^{87}$ as extensively reviewed. ${ }^{88,89}$ Mineralizationinducing peptides installed on synthetic nanoscale scaffolds or biotemplates, such as carbon nanotubes or viruses, respectively, were demonstrated to yield efficiently mineralized nanoparticles (see the papers of Altintoprak et al. ${ }^{8}$ (and references therein), Aljabali et al., ${ }^{90}$ Yang et al. ${ }^{91}$ and Care et al. ${ }^{92}$ ). This has provided new opportunities to characterize the mineralizationinducing and mineralization-guiding effects of different peptides in combination with distinct precursor formulations and in dependence of the underlying carrier surface. Multivalent, repetitively organized biotemplates allow a particularly wellcontrolled display of such effector peptides at predefined surface densities, as shown by the authors for full-length TMV particles a few years ago. ${ }^{8}$ Several types of peptides were tested for their capability to direct silica sheath formation around TMV nanorods in a controllable manner in that study, taking advantage of some features of naturally occurring mineralization-inducing mechanisms as deduced from mineral-precipitating organisms such as diatoms ${ }^{93}$ or glass sponges. ${ }^{94}$ Here, silica condensation occurs at ambient temperatures and pressure at near-neutral $\mathrm{pH}$, with certain proteins and peptides derived thereof acting as key elements. Important examples are the lysine-rich silaffins of diatoms $^{95}$ and the enzymatically active silicatein of glass sponges. ${ }^{94}$ Based on mineral precipitation mechanisms promoted by these proteins, as delineated by the authors recently, ${ }^{20}$ various peptides and biomimetic approaches were designed to accomplish and analyze silica formation under different experimental conditions. ${ }^{96-103}$ These pioneer works have provided clues to predict peptide-enhanced mineralization in solution or on scaffolds and have enabled the generation of well-defined silica structures such as spheres, networks or tubes. Biomineralizationdirecting peptides and protein domains from diatoms are zwitterionic and contain high amounts of basic amino acids, namely, lysine, interspersed by negatively charged or polar amino acid residues (aspartic acid, glutamic acid or serine ${ }^{104,105}$ ). These silaffins are posttranslationally modified, whereby lysine residues can be methylated $\left(\mathrm{R}-\mathrm{N}-\mathrm{CH}_{3}\right)$ counteracting their charge, or bound to even more positively charged polyamines. Serine residues can be phosphorylated $\left(\mathrm{R}-\mathrm{O}-\mathrm{PO}_{3} \mathrm{H}^{-106}\right)$. Alternating arrangements of positively and negatively charged amino acid residues lead to intramolecular so-called charge-relay effects promoting the dehydration of silica precursors and the subsequent condensation of intermediate products, which also seems to account for the enzymatic activity of silicateins. ${ }^{94,98,107,108}$ Kuno et al ${ }^{98}$ validated a charge-relay effect for a peptide composed of five repetitively arranged lysine-aspartic acid (KD) 5 motifs. The peptide induced tetraethoxysilane (TEOS) conversion into silica in a sol-gel process with high efficiency. Thus, the authors previously investigated the mineralization-directing effect of peptides containing different repeat numbers of the KD motif $\left((\mathrm{KD})_{5}\right.$ and $\left.(\mathrm{KD})_{10}\right)$ after immobilization on TMV nanotubes. The $(\mathrm{KD})_{10}$ display achieved a spatially selective, slow and readily controllable deposition of up to $6 \mathrm{~nm}$ silica sheaths around TMV from TEOS in $40 \%(\mathrm{v} / \mathrm{v})$ ethanol within up to $10 \mathrm{~d}$, contrary to the observations for viruses devoid of any peptide or TMV bearing deviating peptides. ${ }^{8}$ The peptides were conjugated to a TMV variant with a mutated $\mathrm{CP}\left(\mathrm{CP}_{\mathrm{Lys}}\right.$, genetically modified by the amino acid exchange $\mathrm{T} 158 \mathrm{~K}^{11}$ ), exposing amino groups for chemical coupling of succinimidyl (NHS) ester-activated (KD) ${ }_{10} \mathrm{C}$ molecules by way of a bifunctional linker.

Simple transfer of the procedure to the RNA-stabilized nanorings containing $\mathrm{CP}_{\text {Lys }}$, ${ }^{6}$ however, was not possible because they did not withstand incubation in the ethanolic TEOS solution. ${ }^{20}$ To test whether or not the concept of silica 'glue' formation around such rings could be followed nevertheless, a different ethanol-free precursor was employed: silicic acid in deionized (DI) water $\left(\mathrm{H}_{2} \mathrm{O}\right)$ at $\mathrm{pH} 5 \cdot 5$, hydrolyzed from tetramethyl orthosilicate $\left(\mathrm{TMOS}^{20}\right)$. Solvent-free reaction conditions have been used 
in several studies to mimic biological silica-forming mechanisms ${ }^{95,97,109,110}$ and are often better compatible with biocomponents. ${ }^{111}$ After $30 \mathrm{~min}$ incubation, (KD) ${ }_{10}$-fashioned nanorings were indeed surrounded by an electron-dense silica shell, whereas control preparations were not. ${ }^{20}$ Hence, it seemed worth optimizing the authors' protocol further, to define conditions appropriate for an in situ sealing of the gaps between soft and hard matter of the envisaged hybrid membranes. This has been the subject of the current study, in conjunction with the crucial question of whether the growing mineral phase remained spatially confined to the outer disk rims, with the central holes left open, or whether the $4 \mathrm{~nm}$ pores became plugged.

The authors exclusively used freshly generated silicic acid precursors for the peptide-guided mineralization, to keep the proportion of small educt species - that is, monosilicic acid ( $\mathrm{Si}$ $\left.(\mathrm{OH})_{4}\right)$ and clusters of low condensation degree - as high as possible, taking into account the different parameters contributing to the formation of oligomers and larger colloidal silica species gradually increasing with time. ${ }^{109,110,112}$ Precursor sols with monosilicic and small silicic acid oligomers will be essential to ensure access of the educts to the narrow gaps between peptidedisplaying disk rims and $\mathrm{SN}$ channels. Particles and aggregates of a few up to several tens of nanometers form in aging silicic acid sols (see the paper of Belton et al. ${ }^{110}$ and references therein). To obtain even silica enrichment selectively at the nanoring rim, hydrolysates of two different alkoxysilanes (TEOS- and TMOSderived silicic acids) were compared. TMV nanorings equipped with the peptide $\mathrm{KD}_{10} \mathrm{C}$ underwent most reproducible sitedirected silica precipitation in hydrolyzed TMOS, confirming previous results. ${ }^{20}$ Because a higher condensation rate is expected at neutral $\mathrm{pH},{ }^{113}$ the silicification performance was examined not only at pH 5.5 (as used with whole TMV particles ${ }^{8}$ ) but also at $\mathrm{pH} 7 \cdot 0$. Silica shell formation was analyzed by monitoring the primary contrast of the electron deflection of pure silica upon use of the TEM without additional contrasting. Selected samples were then employed for high-resolution TEM studies.

Last, but not least, functional analyses of successfully assembled composite membranes demand for pore-in-pore inlays with distinct biopore selectivities, to determine the selective contributions of the protein nanopores to the total permeability of the membranes. This is not only essential for ensemble measurements using membranes with multiple pores, which may exhibit some background leakage due to empty or nonsuccessfully sealed pore channels, but would also be important for comparative single-pore analyses to characterize the permeability of natural and modulated TMV nanorings. Plants enable an easy high-yield preparation of pure TMV particles, the most efficient source of different CP variants for an RNA-mediated assembly of distinct biopore types. Therefore, the authors decided to design TMV mutants that are likely to retain infectivity for tobacco and related plants, but harbor engineered CPs altering the composition of the central channel. A natural TMV particle is composed of 2130 identical CPs, encapsidating a single-stranded RNA
(ssRNA) genome of $6395 \mathrm{nt}$, which contains all genetic information necessary for spreading and accumulating inside stem and leaf tissues. The original TMV length is $300 \mathrm{~nm}$ with a continuous $4 \mathrm{~nm}$ wide longitudinal protein channel surrounded by a 'sandwich' helix of the CPs incorporating the RNA strand. ${ }^{114,115}$ Purified CPs assemble under appropriate conditions (ionic strength, $\mathrm{pH}$, temperature and $\mathrm{CP}$ concentration) into an intermediate ringlike protein oligomer of $\sim 34 \mathrm{CP}$ subunits, which is known as '20S' aggregate and devoid of RNA. In the 1950s, it was demonstrated that this aggregate together with ssRNA was necessary for TMV assembly in vitro under the conditions tested. ${ }^{116}$ Self-organization is initiated by a specific secondary RNA stem-loop structure termed the origin of assembly (OA). ${ }^{117}$ Particle length can be defined by that of the RNA. ${ }^{118,119}$ RNAs of different lengths containing OA sequences will assemble into rodshaped structures as well, which enables predefining the nanotubes' aspect ratio, as developed by the authors' team ${ }^{119-123}$ and used also in other laboratories since, ${ }^{118}$ and even producing various non-linear shapes. ${ }^{124,125}$ In principle, it is also possible to receive ring-shaped CP disks devoid of RNA under proper conditions ( $\mathrm{pH}$, ionic strength or temperature) or by use of certain genetically modified CPs. ${ }^{126-131}$ For the bottom-up assembly of robust, versatile nanorings for biohybrid devices, however, the authors opted for the RNA-guided strategy since minor alterations of buffer conditions and temperature affect the aggregation state of TMV CPs and thus may degrade plain CP complexes. ${ }^{132}$ Consequently, short four-turn $\mathrm{CP}$ helices stabilized by RNAs of $204 \mathrm{nt},{ }^{6}$ termed 'nanorings', were used in this work. Since CPs of plant-infectious TMV exist in many natural variants and can therefore be also genetically engineered to a certain extent, ${ }^{10-12,19,133-135}$ the chemistry of the central channel is accessible to some changes of the lining amino acids. This has been applied here to create TMV as a source for pore-in-pore inlays with altered central holes. Finally, also the RNA scaffold stabilizing the nanorings is a handle for installing functional molecules in close vicinity to the bionanopore, as the RNA's ends are accessible at both ends of the TMV-like helix. Hence, a last challenge was addressed in this study: the modification of the 204 nt RNAs' $5^{\prime}$ ends by bioaffinity anchor molecules and their subsequent combination with $\mathrm{CP}$ under conditions driving in vitro particle assembly. Whether or not $5^{\prime}$-terminal biotin moieties linked to the RNAs would result in an assembly of the desired nanoring structures was analyzed by molecular biology and TEM techniques. These approaches toward differently modified TMVderived bionanopore inlays complete the chain of novel developments advanced in this work, to streamline and refine the fabrication of the envisaged hybrid filtration membrane with a unique and robust combination of tightly interconnected inorganic and biogenic components, apt to collaborate as a functional unit.

\section{Materials and methods}

\subsection{Preparation of nanoporous membranes}

For the preparation of the nanoporous membrane, commercially available SN substrates from Silson Ltd were used, with a size of 
$20 \mu \mathrm{m} \times 20 \mu \mathrm{m}$ and a thickness of $50 \mathrm{~nm}$, supported by a $5 \mathrm{~mm} \times$ $10 \mathrm{~mm}$ silicon support carrier with a pyramidal opening at the backside to provide access to the SN substrate (see Figure S1 in the online supplementary material). Before the structuring process with the helium ion beam, each side of the substrate was exposed to oxygen plasma $(100 \mathrm{~W})$ for $15 \mathrm{~min}$ to remove any contamination on the SN surface. The substrates were then fixed on the sample holder and kept under vacuum until further use. Pores were prepared with a Zeiss Orion NanoFab multi-ion FIB device operated with helium ions. The minimum feature resolution achievable through sputtering depends on the amount of momentum transfer and the size of the focal spot. Helium ions (ion energy $30 \mathrm{keV}$ ) can be focused to a $0.5 \mathrm{~nm}$ dia. beam at a typical acceleration voltage of $25-35 \mathrm{kV}$ and were used to 'drill' small nanopores $(20-30 \mathrm{~nm})$ into the SN substrate. For the experiments described here, the helium beam current was adjusted to 1 and $3 \mathrm{pA}$ through a $5 \mu \mathrm{m}$ aperture at an acceleration voltage of $30 \mathrm{kV}$. For the investigation of the diameters of the inlet pore apertures as a function $(a)$ of the exposure time (between 50 and $4000 \mathrm{~ms}$ ) and (b) of the current ( 1 and $3 \mathrm{pA})$, the ion beam was directed to a point on the SN substrate surface for the corresponding time period. For the preparation of the $6 \times 6$ pore array for nanoring insertion, each position on the substrate was irradiated for $2000 \mathrm{~ms}$ with a current of $3 \mathrm{pA}$. The irradiation experiments were carried out according to the front-side exposure technique shown in Figure S2(a) in the online supplementary material. To investigate the outlet apertures of the pores by AFM, back-side exposure by the HIM (Figure S2(b) in the online supplementary material) was applied, as in the case of front-side exposure the pyramidal shape of the silicon support would otherwise avoid mechanical access of the AFM tip (see experimental details later). For these experiments, the applied currents were 1 and $3 \mathrm{pA}$, as exposure times $0 \cdot 5,1,2$ and $3 \mathrm{~s}$ were chosen.

\subsection{Preparation and purification of RNA-stabilized TMV-based nanorings}

Pore-in-pore nucleoprotein inlays $18 \mathrm{~nm}$ dia. with central $4 \mathrm{~nm}$ pores were assembled in vitro from an RNA scaffold of $204 \mathrm{nt}$ and two or three types of TMV-derived, plant-made CP species (wildtype (WT) $\mathrm{CP}, \mathrm{CP}_{\mathrm{Lys}}$ and, for some tests, $\mathrm{CP}_{\mathrm{Cys}}{ }^{11}$ ) as recently described in detail, ${ }^{6}$ to allow double or triple functionalization of the outer rim by chemical coupling procedures. Prior to nanoring insertion (see later), the RNA-stabilized TMV rings were purified to deplete unassembled CPs and RNA by fast protein liquid chromatography (FPLC). TMV rings were prepared by incubating $3.5 \mathrm{mg} / \mathrm{ml} \mathrm{CP}$ with $0.3 \mathrm{mg} / \mathrm{ml} 204 \mathrm{nt}$ RNA in $75 \mathrm{mM}$ sodium potassium phosphate (SPP), $\mathrm{pH} 7 \cdot 2$ for $16 \mathrm{~h}$ at $25^{\circ} \mathrm{C}$. About $1 \mathrm{mg}$ nanorings with a total $\mathrm{CP}$ concentration of $2 \mathrm{mg} / \mathrm{ml}$ in $75 \mathrm{mM} \mathrm{SPP}$ at $\mathrm{pH} 7 \cdot 2$ was stored for $2 \mathrm{~d}$ at $4^{\circ} \mathrm{C}$ to disassemble higher-order RNA-free CP aggregates, to allow separation of the RNA-stabilized rings from the educts subsequently. Size exclusion chromatography (SEC) was carried out with an Äkta prime system (Amersham Biosciences, now GE Healthcare Life Sciences, Freiburg, Germany) equipped with a gel filtration column (HiPrep 16/60 Sephacryl S-500 High Resolution (GE Healthcare)) at a flow rate of $0.4 \mathrm{ml} /$ min for the $50 \mathrm{mM}$ SPP buffer, $\mathrm{pH} 7 \cdot 2$, supplemented with $150 \mathrm{mM}$ sodium chloride $(\mathrm{NaCl})$ and a fraction volume of $1 \mathrm{ml}$. The ultraviolet (UV) absorbance of the fractions was measured at 260 and $280 \mathrm{~nm}$ in Corning UV-transparent microplates (Merck, Taufkirchen, Germany) with a microplate reader (Infinite 200 Pro, Tecan Austria, Groedig, Austria). Fractions containing the nanorings were concentrated by the use of ultrafiltration devices (100 kDa molecular weight cutoff (MWCO), $4 \mathrm{ml}$ Amicon Ultra

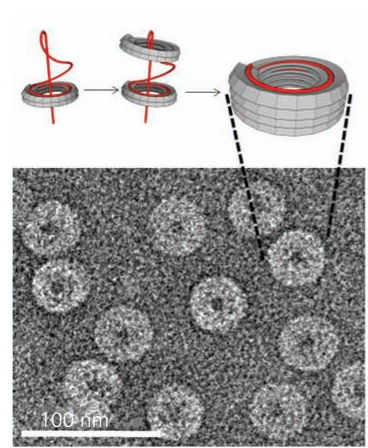

(a)

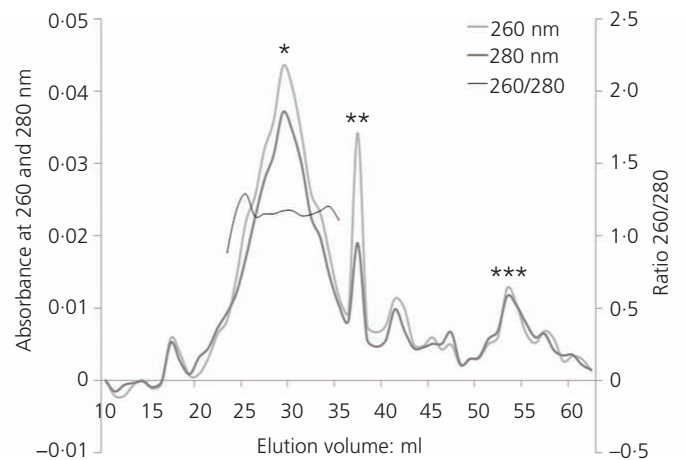

(b)

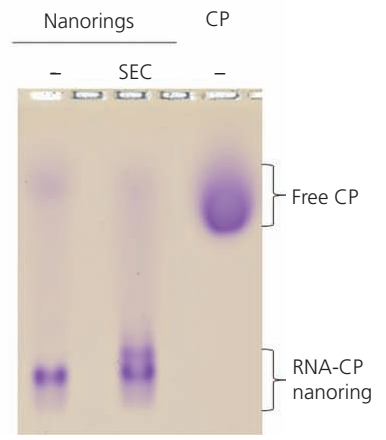

(c)

Figure 2. Preparation of RNA-stabilized TMV nanorings and purification by size SEC. (a) Organization of the short helical TMV-derived pore-in-pore inlays from 68 CP subunits and a 204 nt RNA sandwiched between the CP spiral (red). TEM after uranyl acetate negative staining visualizes the even shape of the structures, their $18 \mathrm{~nm}$ diameter and their central $4 \mathrm{~nm}$ pores (modified partially from Altintoprak et al. ${ }^{6}$ with permission). (b) Nanorings $\left({ }^{*}\right)$ were separated from free ssRNA (**) and CPs (***) by Sephacryl S-500 gel filtration FPLC. The absorbance of fractions was measured at 260 and $280 \mathrm{~nm}$ to identify the fractions containing the nanorings, indicated by their elution volumes. The absorption quotient of $260 \mathrm{~nm} / 280 \mathrm{~nm}$ is in agreement with the expected RNAVCP ratio (1.17 \pm 0.04$)$ and thus indicates purity of the nanorings in the fractions from 25 to $35 \mathrm{ml}$. (c) Native agarose gel electrophoresis of purified nanorings (labeled with SEC) and non-purified nanorings or CP (labeled with -). Proteins in the gel were stained with Coomassie Brilliant Blue R-250 
centrifugal filters, Merck), and concentration efficiency was determined through UV spectroscopy using the TMV extinction coefficient at $260 \mathrm{~nm}(3 \mathrm{ml} /(\mathrm{mg} \mathrm{cm})) .{ }^{136}$ Samples were subjected to native and denaturing gel electrophoresis and transmission electron microscope (TEM) analysis as detailed elsewhere. ${ }^{6,8,23}$

\subsection{Nanoring insertion into SSM template pores}

For the insertion of the TMV inlays into the pores of the SSM membrane, a home-made electrophoresis setup schematically shown in Figure 5(b) was used. The setup consists of two poly (methyl methacrylate) (PMMA) compartments with a volume of $300 \mu \mathrm{l}$ each. Both have a round opening on the side-wall where an O-ring can be placed and can be mounted in a way that the openings are facing each other. Depending on the experiment, either a substrate with or without membrane or just with an O-ring can be mounted between the cells. The screw presses the cells together so that the O-ring can seal the whole setup. For the electrophoretic experiments, one compartment was filled with $300 \mu 175 \mathrm{mM}$ SPP buffer ( $\mathrm{pH} 7 \cdot 2$ ), while the other was filled with the same volume of a TMV nanoring suspension with $2 \cdot 4 \times$ $10^{13}$ nanorings $/ \mathrm{ml}$ in the same buffer. The electrophoretic cells and the SSM were treated in oxygen plasma for $10 \mathrm{~min}$ (Diener plasma cleaner, $100 \mathrm{~W}$ ) before each experiment. The interface between SSM and cells (O-ring) was wetted by $20 \mu 1$ methanol before use, to increase the hydrophilicity for optimized wetting by the buffer solution.

A GPD-X303S direct-current power supply (GW Instek Co.) applied a potential of $400 \mathrm{mV}$ (against silver (Ag)/silver chloride $(\mathrm{AgCl})$ as reference electrode) where the anode was in contact with the nanoring solution. To prove nanoring insertion into the SSM pores indirectly, the current/voltage $(I / U)$ characteristic was investigated at a potential of $400 \mathrm{mV}$ with two LabView controlled multimeters (Keithley 2000, Keithley Instruments Co.), and the decrease in current during the insertion was measured for 30 min. Control experiments made use of the same setup devoid of nanorings, to determine the current decrease resulting from mere charge separation.

\subsection{Electron microscope and AFM investigation}

After electrophoretic nanoring implantation into the solid-state template pores, the respective and control membranes were analyzed by using a SEM and an AFM, respectively. Membranes were removed from the electrophoretic cells and immersed in DI water for $2 \mathrm{~min}$ and dried under a nitrogen gas flow. A Hitachi S-5200 SEM with a transmission mode option was used to investigate the membrane. To increase the contrast in SEM mode, a layer of $2 \mathrm{~nm}$ platinum (Pt) was deposited by sputtering. The Hitachi SEM can also be operated as a scanning transmission electron microscope (STEM) by using the same sample holder. A detector placed on the back side of the sample recorded transmitted electrons during scanning. Both modes operate with an accelerating voltage of $30 \mathrm{kV}$ and an emission current of $10000 \mathrm{nA}$. Image processing was carried out by ImageJ software. For AFM measurements, a multimode AFM from Digital
Instruments operated in tapping mode was used to analyze the membrane surfaces in air. Cantilevers (HQ:NSC18/CR-Au from MikroMasch) with force constants of $2 \cdot 8 \mathrm{~N} / \mathrm{m}$ were used to characterize the pores and biorings. The AFM files were processed by Gwyddion version 2.47 software.

\subsection{Preparation of GNP conjugates with DNA oligonucleotides}

Colloidal GNPs $20 \mathrm{~nm}$ dia. in citrate buffer (\#741965, SigmaAldrich) were used as model objects for studying electrophoretic insertion efficiencies in the presence of DNA exposed on their surface. To this end, they were conjugated with modified DNA oligonucleotides (Biomers, Ulm, Germany). ${ }^{137}$ For the coupling reaction, oligonucleotides (see Table $\mathrm{S} 1$ in the online supplementary material and indicated in the following as oligo$\mathrm{SH})$ with phosphate groups at their $5^{\prime}$ ends for higher colloidal stability due to negative repulsion and thiol groups at their $3^{\prime}$ ends for thiolate-gold bond formation were used. GNPs $\left(5 \cdot 76 \times 10^{11}\right)$ were incubated with $4 \mathrm{mmol}$ oligo-SH at $25^{\circ} \mathrm{C}$ and orbital shaking at 500 revolutions per minute (rpm) for $6 \mathrm{~h}$. Gradually, sodium phosphate buffer, $\mathrm{pH} 7 \cdot 0$ and sodium chloride was added to a final concentration (FC) of 23 and $230 \mathrm{mM}$, respectively. To allow conjugation of the thiol groups to the GNPs, the mixture was incubated at $25^{\circ} \mathrm{C}$ and $500 \mathrm{rpm}$ for $16 \mathrm{~h}$. To remove unreacted oligo-SH, the suspension was centrifuged at $4^{\circ} \mathrm{C}$ and $10000 \mathrm{~g}$ for $20 \mathrm{~min}$ and the supernatant carefully removed from the red oily pellet. The pellet was resuspended in $50 \mathrm{mM}$ sodium chloride to an FC of $0.8 \mathrm{nM}$ oligonucleotide-coated GNPs (oligo-GNPs).

\subsection{Insertion of oligo-GNPs into SSM pores}

The oligo-GNPs were inserted into SSM pores as explained in detail elsewhere. ${ }^{21}$ A chromium $(\mathrm{Cr}) / \mathrm{gold} / \mathrm{SiO}_{x}$ membrane with conical nanopores (front side: $\varnothing 30.2 \pm 4.6 \mathrm{~nm}$; back side: $\varnothing 11 \cdot 2 \pm 4 \cdot 7 \mathrm{~nm}^{5}$ ) was mounted in an electrophoretic chamber. The chamber at the bottom side of the membrane was filled with $50 \mathrm{mM}$ sodium chloride, and the chamber at the top side with $0.8 \mathrm{nM}$ oligo-GNP in $50 \mathrm{mM}$ sodium chloride. Through silver/ silver chloride electrodes, a voltage of $1 \mathrm{~V}$ was applied for $30 \mathrm{~min}$, and the membrane rinsed with DI water for $60 \mathrm{~s}$ and with methanol for $30 \mathrm{~s}$. The insertion rate of the oligo-GNPs into the porous membrane was analyzed in an ultrahigh-resolution field emission SEM (S-5200, Hitachi Ltd, Tokyo, Japan) at $30 \mathrm{kV}$.

\subsection{Fabrication of peptide-equipped RNA-stabilized TMV nanorings for bioinspired silica deposition}

RNA-stabilized TMV nanorings were prepared and functionalized with peptides as described. ${ }^{20}$ In brief, CPs of mutant $\mathrm{TMV}_{\mathrm{Lys}}{ }^{11}$ which exposes lysine residues at the outer surface - were assembled with $204 \mathrm{nt}$ RNA in a 16:1 ratio in $75 \mathrm{mM} \mathrm{SPP,} \mathrm{pH} \mathrm{7 \cdot 2,}$ to yield RNA-stabilized nanorings $s_{\text {Lys. }}$. These were functionalized with a heterobifunctional cross-linker (succinimidyl-( $N$ maleimidopropionamido)-tetraethylene glycol ester) dissolved in dimethyl sulfoxide (DMSO) (\#22104, Thermo Fisher Scientific) added in an excess of 3750 cross-linker molecules per $\mathrm{CP}_{\text {Lys }}$ and purified by gel filtration. Subsequently, the peptide $(\mathrm{KD})_{10} \mathrm{C}$ 
( $\mathrm{K}=$ lysine, $\mathrm{D}=$ aspartic acid and $\mathrm{C}=$ cysteine) was coupled through its thiol group by Michael addition, employing a ratio of 1:2 peptide to CP. Unbound peptides were removed and buffers were exchanged against DI water by gel filtration.

\subsection{Silicification of peptide-equipped RNA-stabilized TMV nanorings with a TEOS hydrolysate}

From TEOS, a silicic acid precursor solution was prepared by hydrolyzing $22.4 \mu \mathrm{l}$ TEOS in $77.6 \mu \mathrm{l} 1 \mathrm{mM}$ hydrochloric acid ( $\mathrm{HCl})$ (with an $\mathrm{FC}$ of $1 \mathrm{M}$ TEOS and $0.78 \mathrm{mM}$ hydrochloric acid) for $10 \mathrm{~min}$ at room temperature (modified from an existing protocol $^{138}$ ). A volume of $11 \cdot 2 \mu$ of the resulting silicic acid solution was added to $22.5 \mu \mathrm{l}$ nanorings $(2 \mathrm{mg} / \mathrm{ml}$; resulting in an FC of $0.26 \mathrm{mM}$ hydrochloric acid with an ionic strength of $1.3 \times 10^{-7} \mathrm{M}$ and $1.3 \mathrm{mg} / \mathrm{ml}$ nanorings; silicic acid species of unidentified concentration) and incubated for $24 \mathrm{~h}$ or $4 \mathrm{~d}$, respectively, under agitation (500 rpm in a horizontal shaker) at $15^{\circ} \mathrm{C}$. The $\mathrm{pH}$ was measured at the beginning of the mineralization reaction and after both $24 \mathrm{~h}$ and $4 \mathrm{~d}$ with a $\mathrm{pH}$ meter (SevenCompact pH/Ion, Mettler Toledo, Giessen, Germany) equipped with a special electrode (InLab Micro, Mettler Toledo, Giessen, Germany). To remove excess silicic acids, the silicification solution containing nanorings was dialyzed three times against $200 \mathrm{ml}$ double-distilled (DD) water at $4^{\circ} \mathrm{C}$ with DD water changes every $1 \mathrm{~h}$, using Slide-A-Lyzer Mini dialysis devices (10 kDa MWCO, Thermo Fisher Scientific, Darmstadt, Germany). For TEM, silicified or control nanorings were deposited on a carbon/Formvar-covered copper grid and analyzed in the absence of any stain. A TEM (Tecnai G2 Sphera electron microscope, FEI, Hillsboro, USA) operated at an acceleration potential of $120 \mathrm{kV}$ and equipped with a 16 megapixel camera (TemCam-F416, TVIPS, Gauting, Germany) was used.

\subsection{Silicification of peptide-equipped RNA-stabilized TMV nanorings with a TMOS hydrolysate}

The silicification process with a hydrolysate of the starting compound TMOS was described by the authors previously. ${ }^{20}$ As detailed in the literature, ${ }^{95,97,139}$ a $1 \mathrm{M}$ silicic acid solution was prepared. Fifteen microliters of TMOS was hydrolyzed by combination with $85 \mu \mathrm{l} 1 \mathrm{mM}$ hydrochloric acid and incubation for $5 \mathrm{~min}$ at room temperature, yielding $1 \mathrm{M}$ silicic acid in $0 \cdot 85 \mathrm{mM}$ hydrochloric acid. To investigate the influence of the $\mathrm{pH}$ value, two different reaction mixtures at $\mathrm{pH} 5 \cdot 5$ and $7 \cdot 0$ were prepared. For mineralization at $\mathrm{pH} 5 \cdot 5$, peptide-equipped or unmodified nanorings were silicified as previously detailed by Lemloh et $a l .{ }^{20}$ For silicification at $\mathrm{pH} 7 \cdot 0$, an identical mixture was prepared but in the presence of $20 \mathrm{mM}$ Tris-hydrochloric acid, $\mathrm{pH} 7 \cdot 0$ and incubated for $30 \mathrm{~min}$, all other parameters as described. $^{20}$ The $\mathrm{pH}$ was measured at the beginning of the mineralization and after $30 \mathrm{~min}$ as described earlier. To remove unreacted silicic acid, the reaction mixture was dialyzed three times against $300 \mathrm{ml} \mathrm{DD}$ water at $4{ }^{\circ} \mathrm{C}$ for $1 \mathrm{~h}$ each, by way of Slide-A-Lyzer Mini dialysis devices (10 kDa MWCO, Thermo Fisher Scientific, Darmstadt, Germany). Silica deposition on the nanorings was analyzed by TEM.

\subsection{Genetic engineering of TMV CP to generate novel inner channel mutants of TMV and TMV-derived nanorings}

To obtain CPs for differently charged inner nanoring pores in conjunction with an accessibility for chemical coupling, a plantinfectious complementary DNA clone of TMV was genetically modified to exchange in the $\mathrm{CP}$ amino acid sequence glutamine $(\mathrm{Gln}, \mathrm{Q})$ at position 99 or asparagine (Asn, N) at position 101 for the functional amino acid lysine (Lys, K), with both sites in close vicinity to the channel-exposed $\mathrm{CP}$ portion. The plasmid p843pe35TMVr. $1^{12}$ encoding the TMV genome was used as DNA template for site-directed mutagenesis by polymerase chain reaction (PCR) of the nucleotides at plasmid base pair positions 7431:7433 of the triplet encoding the amino acid Q99 (in the TMV genome (NC001367): nucleotides 6009-6011) or at plasmid base pair positions 7437:7439 of the triplet encoding the amino acid N101 (in the TMV genome nucleotides 6015-6017), respectively. They were exchanged from CAG to AAG (encoding $\mathrm{K}$ ) to yield TMV$\mathrm{CP}_{\mathrm{Q} 99 \mathrm{~K}}$ or from $\mathrm{AAC}$ to $\mathrm{AAG}$ (encoding $\mathrm{K}$ ) to yield TMV$\mathrm{CP}_{\mathrm{N} 101 \mathrm{~K}}$. For mutagenesis of WT TMV into the respective variants, the complete plasmid p843pe35TMVr.1 (isolated from Escherichia coli (E. coli) NM522 (New England Biolabs (NEB), Massachusetts, USA)) was amplified through PCR (initial denaturation at $98^{\circ} \mathrm{C}$, $30 \mathrm{~s} ; 12$ cycles of $98^{\circ} \mathrm{C}, 10 \mathrm{~s}, 68^{\circ} \mathrm{C}, 20 \mathrm{~s}, 72^{\circ} \mathrm{C}, 6 \mathrm{~min}$ ) by use of the primers listed in Table $\mathrm{S} 1$ in the online supplementary material with Q5 polymerase (NEB). After product purification (QIAquick PCR Purification Kit, Qiagen, Hilden, Germany) and degradation of the original plasmid p843pe35TMVr.1 by restriction digestion with DpnI (NEB), the final PCR product was transformed into E. coli NM522 according to standard molecular cloning procedures. ${ }^{140}$ Mutated plasmids p843-CP $\mathrm{Q}_{\mathrm{Q} 9 \mathrm{~K}}$ and $\mathrm{p} 843-\mathrm{CP}_{\mathrm{N} 101 \mathrm{~K}}$ were amplified and isolated according to Plasmid Mini Kit's (Qiagen) instructional information. Sequence identity was confirmed by commercial DNA sequencing (LGC Genomics GmbH, Berlin, Germany).

\subsection{Isolation and chemical modification of TMV $\mathrm{CP}_{\mathrm{Q} 9 \mathrm{~K}}$ and $\mathrm{CP}_{\mathrm{N} 101 \mathrm{~K}}$}

The authors have recently published a step-by-step instruction on farming, harvesting and analyzing TMV variants from plants, which may be a useful accessory protocol for the following brief description. ${ }^{23}$ Nicotiana tabacum plants were inoculated with p843$\mathrm{CP}_{\mathrm{Q} 99 \mathrm{~K}}$ or $\mathrm{p} 843-\mathrm{CP}_{\mathrm{N} 101 \mathrm{~K}} 28 \mathrm{~d}$ after sowing. Leaves 4 and 5 were dusted with carborundum. Four micrograms of plasmid DNA was diluted in $50 \mathrm{mM}$ sodium phosphate buffer, $\mathrm{pH} 7 \cdot 0$ to $80 \mathrm{ng} / \mathrm{ml}$ (FC) plasmid DNA, dropped onto the powdered leaves and inoculated by rubbing. Systemically infected leaves were harvested $45 \mathrm{~d}$ post inoculation (dpi) and frozen in liquid nitrogen. Mutated TMV particles were isolated according to an existing protocol. ${ }^{141}$ The concentration of isolated TMV particles was determined by UV spectroscopy using the TMV extinction coefficient at $260 \mathrm{~nm}$ $(3 \mathrm{ml} /(\mathrm{mg} \mathrm{cm}))$. For TEM, TMV particles were deposited on a carbon/Formvar-covered copper grid and negatively stained with $2 \%$ uranyl acetate. A TEM (Tecnai G2 Sphera electron microscope, FEI, Hillsboro, USA) operated at an acceleration potential of $120 \mathrm{kV}$ and equipped with a 16 megapixel camera (TemCam-F416, TVIPS, 
Gauting, Germany) was used. To test whether the lysine residues in the inner channel were accessible for chemical coupling, TMV particles (FC $0.1 \mathrm{mg} / \mathrm{ml}$ ) were chemically modified with Atto 488 $\mathrm{N}$-hydroxysuccinimidyl ester (FC $0 \cdot 13 \mathrm{mM}$ Atto 488-NHS, Atto-Tec, Siegen, Germany) in $10 \mathrm{mM}$ SPP at $\mathrm{pH} 7 \cdot 2$ for $1 \mathrm{~h}$ at $37^{\circ} \mathrm{C}$ under agitation at $500 \mathrm{rpm}$. After chemical coupling, modified proteins were investigated by sodium dodecyl sulfate-polyacrylamide gel electrophoresis (SDS-PAGE) ${ }^{142}$ in a polyacrylamide (PA) gel ((FC) $15 \%$ acrylamide/bisacrylamide $(37 \cdot 5: 1))$. The assay is selective for genetically introduced amino groups since WT TMV from plants does not provide any naturally accessible amino side-chains and its CPs are N-terminally acetylated (see the papers of Geiger et al. ${ }^{11}$ and Kadri et al. ${ }^{143}$ and references therein). Fluorescent signals of Atto 488-labeled proteins were recorded with a ChemiDoc XRS (BioRad) in UV light. Proteins in the gel were subsequently stained with Coomassie Brilliant Blue R-250 (Serva) dissolved at a concentration of $2.5 \mathrm{~g} / \mathrm{l}$ in $10 \%(\mathrm{v} / \mathrm{v})$ acetic acid and $40 \%(\mathrm{v} / \mathrm{v})$ ethanol.

\subsection{Fabrication of nanorings with biotinylated ssRNA $5^{\prime}$ ends}

For the generation of nanorings with biotin-functionalized RNA 5 ends, two OA-containing RNAs of different lengths (204 and $500 \mathrm{nt})$ were modified with a $5^{\prime}$-EndTag nucleic acid labeling system (\#MB-9001, Vector Laboratories, Burlingame, California, USA) according to the supplier's information. First, the ssRNAs containing the core sequence of the TMV OA ${ }^{144}$ were synthesized by in vitro transcription as described. ${ }^{6}$ To remove the $5^{\prime}$-phosphate group for the subsequent $5^{\prime}$ end modification, $0 \cdot 3 \mathrm{nmol}$ of each ssRNA was supplemented with $0 \cdot 5 \mu$ universal reaction buffer and $0 \cdot 5 \mu \mathrm{l}$ alkaline phosphatase (both reagents supplied with the $5^{\prime}$ EndTag system) in a final volume of $5 \mu \mathrm{l}$ and incubated for $30 \mathrm{~min}$ at $37^{\circ} \mathrm{C}$. Subsequently, the reaction mixture was heated for $5 \mathrm{~min}$ at $70^{\circ} \mathrm{C}$ and chilled on ice for $5 \mathrm{~min}$. The mixture was supplemented with $0.2 \mu \mathrm{l}$ universal reaction buffer, $0.5 \mu \mathrm{l}$ ATP $\gamma \mathrm{S}$ and $1 \mu \mathrm{l}$ $\mathrm{T} 4$ polynucleotide kinase (all supplied with the $5^{\prime}$-EndTag system) in a final volume of $10 \mu \mathrm{l}$ and incubated for $30 \mathrm{~min}$ at $37^{\circ} \mathrm{C}$. The modified ssRNAs now with thiophosphates at their $5^{\prime}$ ends were labeled with a 1250-fold molar excess of EZ-Link maleimide-(PEG) ${ }_{11}$-biotin linker dissolved in DMSO (\#21911, Thermo Fisher Scientific, Massachusetts, USA) for $2 \mathrm{~h}$ at room temperature under agitation in a horizontal shaker at $400 \mathrm{rpm}$. The biotin-labeled ssRNAs were purified by phenol extraction and concentrated by ethanol precipitation. To each ssRNA reaction mixture, $2 \cdot 33$ volumes DD water and $3 \cdot 33$ volumes Roti-Phenol (Carl Roth, Karlsruhe, Germany) were added and mixed thoroughly. The ssRNA-containing upper phase was transferred to a new reaction tube. To precipitate the ssRNA, $2 \cdot 7$ volumes $95 \%$ ethanol and 0.05 volume precipitant (supplied with $5^{\prime}$-EndTag nucleic acid labeling system) was added, mixed and centrifuged for $30 \mathrm{~min}$ at $13000 \mathrm{~g}$. The ssRNA pellet was washed with $70 \%$ ethanol for $3 \mathrm{~min}$ and recovered at $13000 \mathrm{~g}$. The supernatant was discarded, and the pellet was dried at room temperature and dissolved in DD water.

Nanorings with encapsidated biotin-labeled ssRNA were prepared by in vitro assembly. To this end, RNA-free CPs were isolated, ${ }^{145}$ their concentration was determined ${ }^{116}$ by use of an extinction coefficient of $1.3 \mathrm{ml} /(\mathrm{mg} \mathrm{cm})$ and they were incubated with biotin-labeled (and as a control with unmodified) ssRNAs in a $1: 15$ weight ratio of $0 \cdot 2 \mu \mathrm{g} / \mu \mathrm{l}$ ssRNA and $3 \mu \mathrm{g} / \mu 1 \mathrm{CP}_{\mathrm{wt}}$ in $75 \mathrm{mM}$ $\mathrm{SPP}$ at $\mathrm{pH} 7 \cdot 2$ for $16 \mathrm{~h}$ at $25^{\circ} \mathrm{C}$. Products were analyzed by native gel electrophoresis as described. ${ }^{6}$

\subsection{RNase A protection assay to investigate the encapsidation status of biotin-labeled ssRNAs}

To test whether the biotin-labeled ssRNA was efficiently encapsidated inside a CP helix, an RNase A protection assay was performed according to a previously published method ${ }^{146}$ with modifications. With reference to the CP concentration, $2 \cdot 5 \mu \mathrm{g} / \mu \mathrm{l}$ FC of RNA-stabilized disks (initial concentration: $3 \mu \mathrm{g} / \mu \mathrm{l}$ ) were treated with $16.7 \mu \mathrm{g} / \mathrm{ml} \mathrm{FC} \mathrm{RNase} \mathrm{A} \mathrm{(concentration} \mathrm{of} \mathrm{stock}$ solution: $0 \cdot 1 \mu \mathrm{g} / \mu \mathrm{l}$ ) in $75 \mathrm{mM}$ SPP, $\mathrm{pH} 7 \cdot 2$ for $15 \mathrm{~min}$ at $30^{\circ} \mathrm{C}$. To degrade RNase A and the CPs, the reaction was stopped by the addition of $0.8 \mu \mathrm{g} / \mathrm{ml} \mathrm{FC} \mathrm{proteinase} \mathrm{K}$ (stock solution: $10 \mu \mathrm{g} / \mu \mathrm{l}$ ) followed by incubation for $10 \mathrm{~min}$ at $30^{\circ} \mathrm{C}$. To avoid degradation of the previously protected and subsequently released RNA, $13 \mathrm{mM}$ (FC) ribonucleoside vanadyl complex (stock solution: $200 \mathrm{mM}$, NEB, Massachusetts, USA) and 1\% (w/v) FC SDS (stock solution: $10 \%(\mathrm{w} / \mathrm{v})$ ) was added and incubated for $10 \mathrm{~min}$ at $37^{\circ} \mathrm{C}$. For final RNA release, one-tenth volume of $200 \mathrm{mM}$ Tris-hydrochloric acid $\mathrm{pH} 9.5$ was added and incubated for $10 \mathrm{~min}$ at $65^{\circ} \mathrm{C}$. The initially $\mathrm{CP}$-protected ssRNA with and without biotin label was analyzed by urea $\mathrm{PAGE}^{147}$ and subsequent transfer of the ssRNA from the PA gel onto a nylon membrane. ${ }^{148}$ PA gels were prepared with 19:1 acrylamide/ bisacrylamide solution (Carl Roth, Karlsruhe, Germany) to an FC of $7 \% ; 0.42 \mathrm{mg} / \mathrm{ml} \mathrm{FC}$ urea; Tris/borate/ethylenediaminetetraacetic acid (EDTA) (TBE) buffer ((FC) $89 \mathrm{mM}$ Tris, (FC) $89 \mathrm{mM}$ boric acid, (FC) 2 mM EDTA (disodium salt)); (FC) $0 \cdot 1 \%$ (v/v) $N, N, N^{\prime}$, $N^{\prime}$-tetramethylethylene diamine (TEMED); and (FC) $0 \cdot 1$ (w/v) ammonium persulfate (APS). The gel was prerun for $30 \mathrm{~min}$ at $400 \mathrm{~V}$. The ssRNA was denatured by the addition of $1 \times$ RNA loading dye (\#R0641, Thermo Fisher Scientific) for $10 \mathrm{~min}$ at $95^{\circ} \mathrm{C}$, separated in the PA gel for $65 \mathrm{~min}$ at $400 \mathrm{~V}$ and stained with SYBR Gold nucleic acid gel stain (Thermo Fisher Scientific) diluted 1:10000 in TBE buffer. ${ }^{149}$ The ssRNA was transferred from the gel onto a nylon membrane (Amersham Hybond-NX, GE Healthcare Life Sciences, Freiburg, Germany) prewetted with DD water in a semidry blotter (Bio-Rad, Munich, Germany) for $60 \mathrm{~min}$ at $24 \mathrm{~V}$ and $4^{\circ} \mathrm{C}$ as described previously by Pall and Hamilton. ${ }^{148}$ The membrane was air-dried, and the ssRNA was cross-linked by UV light exposure for $2 \mathrm{~min}$ at $70 \cdot 000 \mu \mathrm{J} / \mathrm{cm}^{2}$. The membrane was washed with buffer A for $5 \mathrm{~min}(0 \cdot 1 \mathrm{M}$ maleic acid, $0 \cdot 15 \mathrm{M}$ sodium chloride, $\mathrm{pH} 7 \cdot 5$ adjusted with sodium hydroxide) supplemented with $0 \cdot 3 \%(\mathrm{v} / \mathrm{v})$ Tween 20 and blocked with buffer $\mathrm{B}$ for $1 \mathrm{~h}(10: 1$ ratio of buffer A to $10 \%(\mathrm{w} / \mathrm{v})$ blocking reagent (Roche, Mannheim, Germany)) at room temperature. To detect the biotin-labeled ssRNA, the membrane was incubated for $30 \mathrm{~min}$ at room temperature in buffer B containing streptavidin-alkaline-phosphatase (SAP) conjugate (\#11093266910, Roche) diluted 1:5000. Excess SAP conjugate 
was removed by three washing steps with buffer A supplemented with $0 \cdot 3 \%(\mathrm{v} / \mathrm{v})$ Tween 20 for $10 \mathrm{~min}$ at room temperature. The membrane was equilibrated in buffer $\mathrm{C}(0 \cdot 1 \mathrm{M}$ Tris, $0 \cdot 1 \mathrm{M}$ sodium chloride, $\mathrm{pH} 9.5$ adjusted with hydrochloric acid) for $5 \mathrm{~min}$ and incubated in reaction buffer (Disodium 3-(4-methoxyspiro \{1,2dioxetane-3,2'-(5'-chloro)tricyclo $\quad[3.3 .1 .13,7]$ decan $\}-4-y 1)$ phenyl phosphate (CSPD) ready-to-use (\#11755633001, Roche) diluted 1:200 in buffer $\mathrm{C}$ ) for $10 \mathrm{~min}$ at $37^{\circ} \mathrm{C}$. The signal of the alkaline phosphatase-mediated conversion of CSPD into a metastable phenolate anion emitting light upon its decomposition was detected by exposing the membrane to an X-ray film (\#088K0795, $13 \mathrm{~cm} \times 18 \mathrm{~cm}$ Kodak BioMax XAR film, Sigma-Aldrich) followed by developing and scanning.

\section{Results and discussion}

A recently proposed combination of inorganic, freestanding porous SSM templates functionalized by plant-virus-derived biomolecular inlays with central $4 \mathrm{~nm}$ protein pores has been advanced by means of several newly introduced preparation steps. The achievements include $(a)$ an HIM-enabled FIB procedure granting fast access to precisely sized and spatially arranged conical nanopores in commercially available SN substrates; (b) their equipment with TMV-deduced pore-in-pore nanorings in an electrophoretic cell; (c) tests for potential improvements of the insertion efficiency by additional negative charges; $(d)$ new protocols for immobilizing the biopores in situ through a self-luting process guided by silicification-directing peptides installed on the outer nanoring rim, in combination with silicic acid precursors of low oligomerization state and thus size; and (e) both the design and generation of building blocks for novel TMV nanorings with modulated protein pore charge, selective chemical addressability and/or a single biotin docking site for streptavidin-conjugated molecules introduced at the scaffold RNAs' exposed 5'end. The consecutive steps and their intermediate or final products are presented in the order of their preparation and interconnection, to lead eventually to robust biohybrid filtration and sorting arrays adaptable to selective molecular discrimination tasks.

\subsection{Nanoporous inorganic membrane templates}

The pore-in-pore approach was realized by an electrophoretically driven insertion of perforated viral nanorings into size-adapted pores of an SSM template, with the pores generated by degradation of the SN with a helium ion beam. Two requirements in terms of the pore properties had to be met: the pores should have $(a)$ an inlet aperture wide enough to let the nanorings pass inside the pores and $(b)$ outlet pore apertures small enough to avoid diffusion of the rings through the SSM pores, so that they became trapped inside. To meet both requirements, a conical shape of the pores is needed as schematically shown in Figure 1. Using single spot exposure, different doses of helium ions for the irradiation of the SN substrate were used to prepare arrays of pores. By variation of the beam current and exposure times, pores with different diameters were created. The pore diameter is a function of the ion dose $D$, which depends on the beam current, exposure time and irradiated area, according to the equation
1. $\log (d)=a+b \log (D)$

where $d$ is the pore diameter and $a$ and $b$ are correlation constants. However, typically two regimes are observed reflecting different growth rates depending on the nanopore shape, ${ }^{43}$ which changes from conical to a more cylindrical shape with increasing exposure time and thus dose. After breaking through the membrane, the milling yield is no longer dominated by the direct beam incidence, but rather by grazing incidence of the beam on the side walls. Such a process can be expected to result in more cylindrical pore shapes at extended milling times.

In the first experiment, the effect of different currents ( 1 and $3 \mathrm{pA}$ ) and different exposure times between 50 and $4000 \mathrm{~ms}$ on the pore diameters created in the SN substrate was investigated. AFM was used to measure the resulting pore sizes. Figure 3 shows the corresponding results: for all cases, pore diameters increased with increasing current and with increasing exposure time, as long as $t<1000 \mathrm{~ms}$. For prolonged exposure between 1000 and $2000 \mathrm{~ms}$, the diameters increased more slowly and almost reached a plateau value, even for exposure times $>2000 \mathrm{~ms}$, which can be explained by a change in nanopore shape $^{43}$ as described earlier (Figure 3, top). The ion doses for
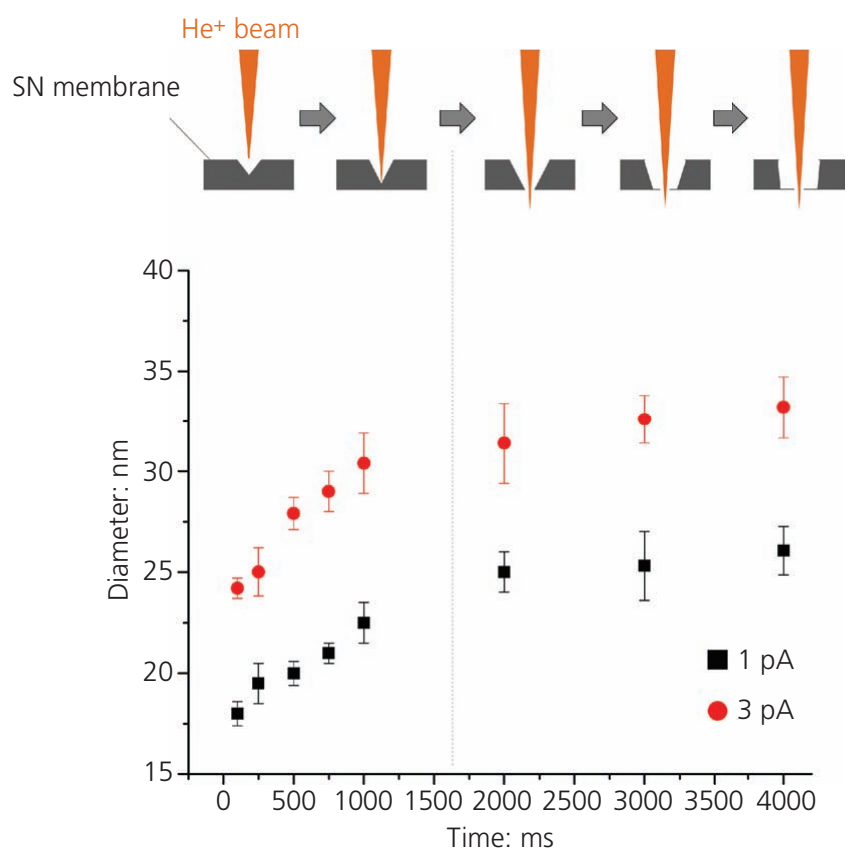

Figure 3. Inlet diameter of pores prepared by helium ion beam front-side exposure on an SN substrate as a function of different currents and exposure times. The reduced slope regime beyond $1000 \mathrm{~ms}$ can be explained by the breakthrough of the beam through the SN substrate (see sketch at the top). In this regime, the change in pore diameter is reduced since the milling is dominated by grazing incidence of the beam on the side-walls, which can be expected to create more cylindrical pore shapes 
Bioinspired, Biomimetic and Nanobiomaterials Volume 8 Issue BBN1
Improved manufacture of hybrid membranes with bionanopore adapters capable of self-luting

Altintoprak, Farajollahi, Seidenstücker et al. each spot corresponding to the data points in Figure 3 are summarized the Table S2 in the online supplementary material.

The diameters of the inlet pore apertures prepared by front-side ion beam exposure (Figure S2(a) in the online supplementary material) could be investigated by AFM for each exposure time or current. However, it was not possible to evaluate whether the helium ion dose had been high enough to produce the desired outlet apertures (see aforementioned second requirement) at the other side of the membrane, as the depth of the pyramidal cavity $(380 \mu \mathrm{m})$ in the back of the SSM-supporting silicon frame obviated mechanical contact between the SN membrane's back side and the AFM tip, which itself has a height of just $4-5 \mu \mathrm{m}$ (Figure S2(c) in the online supplementary material). Therefore, the back-side exposure (Figure S2(b) in the online supplementary material) approach was applied, to prepare the outlet apertures on the front side of the membrane. Thereafter, successfully produced outlet apertures were accessible at the front side of the SN membrane for AFM and SEM analyses.

AFM analysis of an SN substrate irradiated from the back side revealed that for $1 \mathrm{pA}$ and an exposure time of $t \leq 1 \mathrm{~s}$, no backside pore openings could be recognized at all, while for an exposure time $t \geq 2 \mathrm{~s}$ at $1 \mathrm{pA}$ and for $t \geq 1 \mathrm{~s}$ at $3 \mathrm{pA}$, the irradiation dose was high enough to produce continuous pores (Figure 4(a)). This result was confirmed by an investigation by STEM, to measure the relative amount of electrons passing the SN substrate in those areas that had been exposed to the helium ion beam (Figures S3(a)-S3(d) in the online supplementary material). The finding is in agreement with the plateau values of the inlet pore diameters observed for currents of 1 and $3 \mathrm{pA}$ and exposure times $>2000 \mathrm{~ms}$ (compared to Figure 3). Figure 4 shows the STM images of the inlet (Figure 4(a)) and the STM image of the outlet aperture (Figure 4(b)) of one and the same pore, prepared by front-side exposure at $3 \mathrm{pA}$ for $3000 \mathrm{~ms}$. Both SSM sides were coated with a $2 \mathrm{~nm}$ thick layer of platinum before the SEM images were taken, to avoid any charging effects. With an inlet aperture of $25 \mathrm{~nm}$ and a corresponding outlet aperture of $16 \mathrm{~nm}$, the requirements mentioned earlier are met to make sure that the nanorings can be trapped inside the continuous pores.

\subsection{Preparation and purification of TMV nanorings}

For inserting TMV-derived nanorings into such SSM templates with pores of appropriate dimensions, the nucleoprotein assemblies were prepared from short OA-containing RNA scaffolds and TMV $\mathrm{CP}$ preparations as described (Figure $\left.2(\mathrm{a})^{6}\right)$. In addition, they were purified by SEC to remove non-integrated RNA and CP molecules and thus to prevent clogging of the SSM pores with RNA strands or higher-order CP aggregates. This was regarded important for the novel type of inorganic template with its much lower number of pore channels compared to previously applied $\mathrm{SSMs}^{7}$ and also essential for identifying successfully implanted nanorings without much doubt, if similarly sized nanoparticles were depleted from the source suspension. At room temperature, RNA-free CP aggregates of $18 \mathrm{~nm} \times 4.6 \mathrm{~nm}$ may form, which resemble the

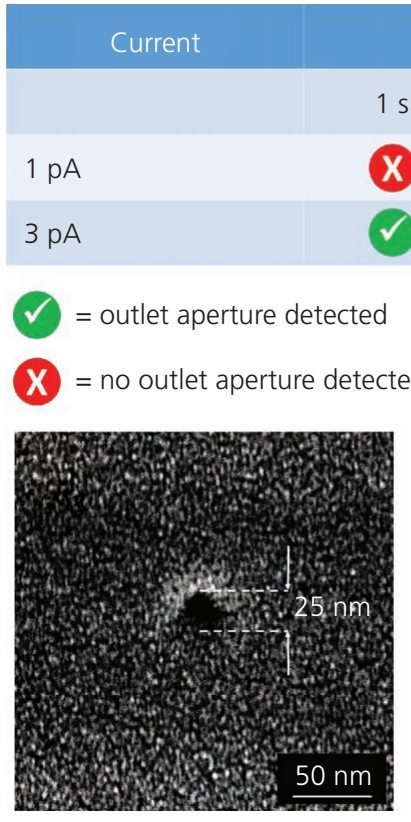

(b) (a)

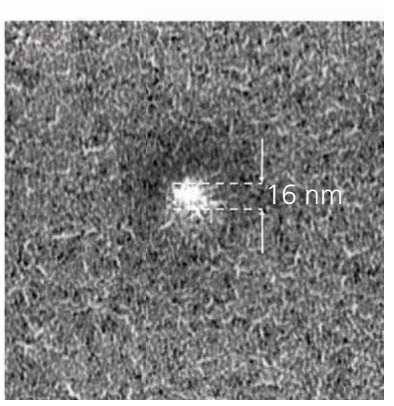

(c)
Figure 4. Parameters of helium ion beam adjustment for fabricating continuous, trough-shaped nanopores of dimensions allowing the insertion of peptide-equipped, TMV-derived nanoporous pore-in-pore inlays (outer $d \approx 20 \mathrm{~nm}$ ). (a) Matrix of the results, obtained by AFM-based evaluation of the pore outlets. SEM images of (b) an inlet aperture and (c) STEM image of the corresponding outlet aperture of one and the same pore, prepared by the front-side exposure approach. Both sides were coated with a $2 \mathrm{~nm}$ thick platinum layer to avoid charging effects

RNA-stabilized nanorings $(18 \mathrm{~nm} \times 9 \cdot 2 \mathrm{~nm})$. Hence, the nanoring preparations were incubated at $4^{\circ} \mathrm{C}$ for $48 \mathrm{~h}$, to disassemble RNAfree CP oligomers into monomers ${ }^{127}$ prior to SEC. The SEC profile of the absorbances at 260 and $280 \mathrm{~nm}$ displays the elution volume of the RNA-stabilized nanorings, the $204 \mathrm{nt}$ RNA and the free CPs (Figure 2(b)). The elution volume from 25 to $35 \mathrm{ml}$ contained the RNA-scaffolded nanorings and exhibited a prominent peak with a $260 \mathrm{~nm} / 280 \mathrm{~nm} \mathrm{UV}$ absorption ratio of $1 \cdot 17$ $\pm 0 \cdot 04$, similar to the ratio of $\mathrm{TMV}_{\mathrm{wt}}$ particles $\left(1 \cdot 17\right.$ to $\left.1 \cdot 2^{150}\right)$. Two additional peaks were detected at an elution volume of $37 \mathrm{ml}$ with a $260 \mathrm{~nm} / 280 \mathrm{~nm}$ UV absorption ratio of $1 \cdot 8$, which is a typical value for pure RNA, and an elution volume of $51-55 \mathrm{ml}$ with a $260 \mathrm{~nm} / 280 \mathrm{~nm} \mathrm{UV} \mathrm{absorption} \mathrm{ratio} \mathrm{of} 0.9 \pm 0 \cdot 1$, comparable to the ratio of purified $\mathrm{CP}_{\mathrm{wt}}(0 \cdot 8)$ used in these experiments for the assembly reaction. The elution volumes expected to contain the RNA-stabilized rings were combined and analyzed by native gel electrophoresis (Figure 2(c)) and TEM to verify the enrichment of the desired structures. The resulting gels revealed the bands characteristic of RNA-stabilized disks. Compared to pure CPs with a lower net charge, the electrophoretic mobility of RNA-containing rings is enhanced due to the additional negative charge of the RNA phosphate backbone. To exclude that subsequently released CP subunits disturbed the preparation and characterization of the bioinorganic hybrid 


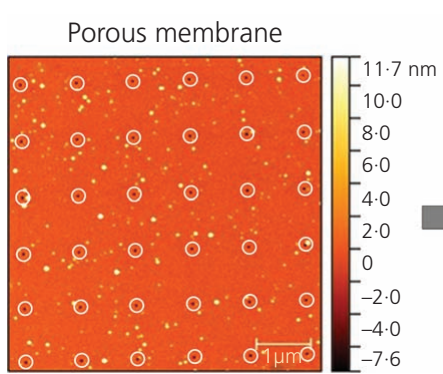

(a)

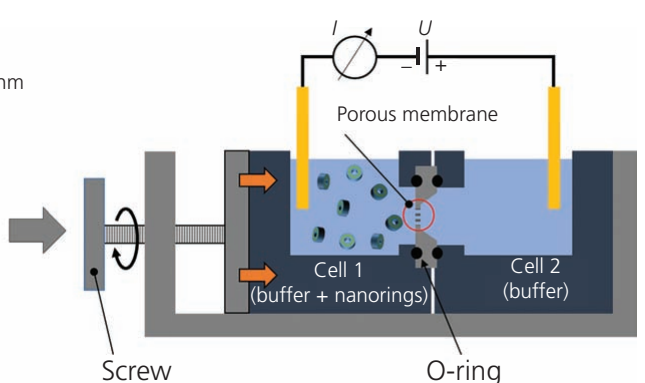

(b)

Figure 5. (a) AFM image of a $6 \times 6$ nanopore array with an average inlet pore diameter of $31 \mathrm{~nm}$. Each pore is marked with a white circle for better visualization. The ion current and exposure time were set to $3 \mathrm{pA}$ and $2000 \mathrm{~ms}$, respectively. (b) Experimental setup for the electrophoresis-driven insertion of the nanorings

membranes, SEC-purified disks were applied for the insertion experiments within the next $48 \mathrm{~h}$.

\subsection{Nanoring insertion}

For the insertion of TMV-based nucleoprotein nanorings into the membrane pores, inlet pore aperture diameters of at least $20 \mathrm{~nm}$ were required, while the opposite outlet apertures should not exceed a diameter of $18 \mathrm{~nm}$ as the disks had to be trapped. According to Figure 3, the pore sizes corresponding to the currents of 1 and $3 \mathrm{pA}$ resulted in average inlet pore diameters of 25 and $32 \mathrm{~nm}$, respectively, after an irradiation time of $2000 \mathrm{~ms}$, and thus meet the requirements. In Figure 5(a), the AFM frontside image of a $6 \times 6$ pore array membrane is shown. The pores were prepared with a current of $3 \mathrm{pA}$ and an irradiation time of $2000 \mathrm{~ms}$; the interporous distance was set to $1 \mu \mathrm{m}$. The dotlike, elevated (bright) particulate features visible in Figure 5(a) appeared after the milling procedure.

To enable implantation of the pore-in-pore inlays in an electric field, the membrane module was mounted as diaphragm between two PMMA cells of an electrophoretic device (Figure 5(b)). The volume of cell 1, which faces the front side of the SN membrane with the inlet SSM pore apertures, was filled with $300 \mu$ of a nanoring suspension $\left(2.4 \times 10^{13}\right.$ nanorings $\left./ \mathrm{ml}\right)$ in SPP buffer, while cell 2 was filled with buffer without nanorings. As the nucleoprotein disks have a negative net charge, the voltage applied between cell 1 (cathode compartment) and cell 2 (anode compartment) induced movement of the disks along the electric field gradient in the direction of cell 2, resulting in a transport of the disks into the inlet apertures of the $\mathrm{SN}$ membrane pores. A scheme of the electrophoretic setup is shown in Figure 5(b); the detailed parameters for the insertion experiments are described in the experimental part.

To evidence the electrophoresis-driven insertion of the biopore adapters into the SSM pores, the current over time was investigated for two cases: in the first one, both compartments of the electrophoresis device (Figure 5(b)) were filled with pure SPP buffer. Due to the applied potential of $400 \mathrm{mV}$, an electric field forms between the two cells and along the cross-section of the SN membrane. As a result, anions from cell 1 move through the pores of the membrane into cell 2 , while the cations from cell 1 move in the opposite direction. This causes the current, which can be measured as a function of time. The red circles in Figure 6 show the current decrease, resulting from the formation of an electric counter field, which is increasing with the number of exchanged ions. As soon as the counterfield compensates for the electric field formed by the potential, no current is detected anymore, which was the case after $30 \mathrm{~min}$ in the authors' experimental setup. If cell 1 contained a suspension of nanorings in the same buffer, a similar behavior of the current over time was observed (black squares in Figure 6); however, the current was significantly reduced at all time points in comparison to that obtained with a nanoring-free buffer. The only exception to this was a comparable current for both the nanoring-containing and the control setup, as in the initial stages of the electrophoretic separation the buffer ions - with a much higher hydrodynamic mobility than the

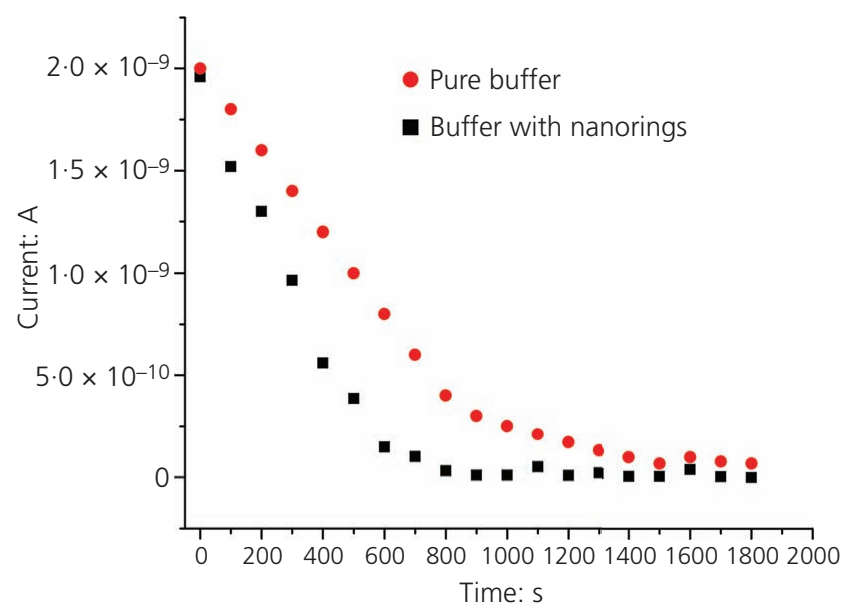

Figure 6. Currents over time measured across the SN membrane consisting of a $10 \times 10$ nanopore array (prepared by front-side exposure at $3 \mathrm{pA}$ for $2 \mathrm{~s}$ ) with the electrophoretic device (see Figure 5(b)) for two cases: (a) both cells are filled with pure buffer solution (red circles) and (b) cell 1 is filled with a buffered nanoring suspension and cell 2 is filled with pure buffer (black squares) 
Bioinspired, Biomimetic and Nanobiomaterials Volume 8 Issue BBN1
Improved manufacture of hybrid membranes with bionanopore adapters capable of self-luting

Altintoprak, Farajollahi, Seidenstücker et al. disks - are predominantly responsible for charge transfer between the compartments. The fact that in the case of the disks for longer times lower currents were measured can be explained by the increased number of nanorings inserted into the membrane pores over time. Depending on the insertion geometry of the nanorings inside the SSM pores, this leads to either $(a)$ a significant increase in the resistance of the pore due to the reduced effective crosssection available for the ions to diffuse through the corresponding pore or $(b)$ even a complete blocking in case of several nanorings inserted, abolishing any diffusion of ions through the pore. Although it is not clear how many charges - if at all - of the nanorings remain accessible after insertion, and in how far those charges influence the formation of the electric counter field, it can be clearly claimed that the differences in the currents for the two cases shown in Figure 6 are not overcompensated by any kind of 'bypass pathways' of the charge carriers through non-occupied SSM pores.

To investigate the success of nanoring implantation into the SSM template pores by the electrophoresis, membranes were subjected to AFM analysis. Figure 7(a) shows the topography image of a $4 \times$ 4 nanopore array before the insertion experiment. To identify the pores more clearly, the $z$-scale was altered to increase the image contrast (Figure 7(b)). After the insertion experiment (Figure 7(c)), the diameters of some pores appear obviously smaller or changed. This can be seen more clearly in Figure 7(d) which shows the same surface area as Figure 7(c), but with increased contrast. The red circles represent those pores where complete or partial
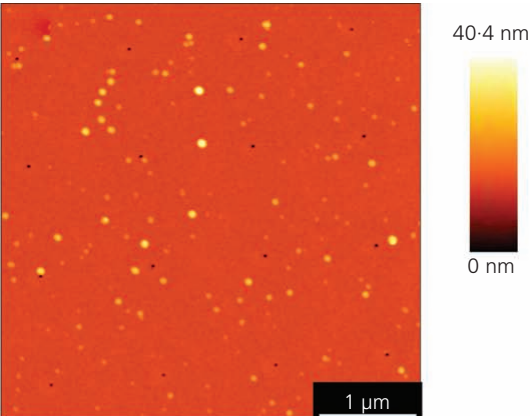

(a)

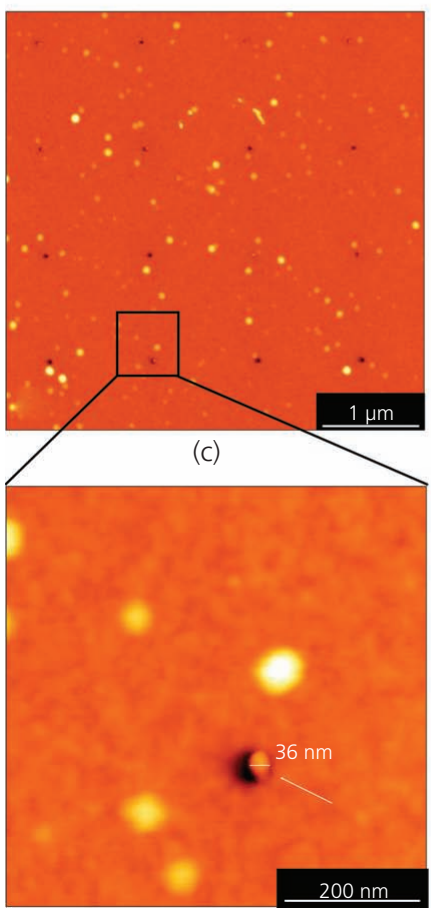

(e)
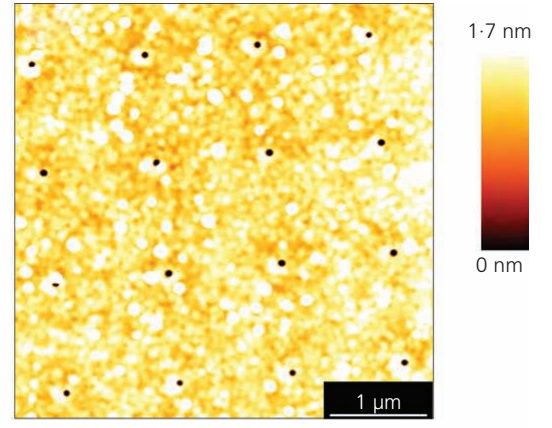

(b)

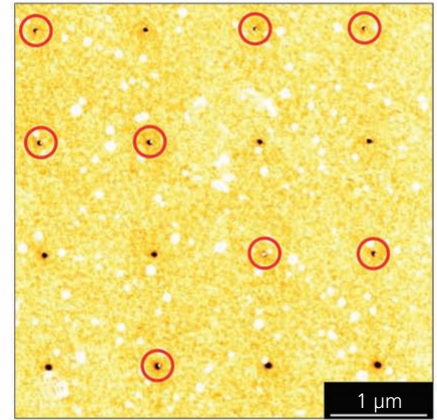

(d)

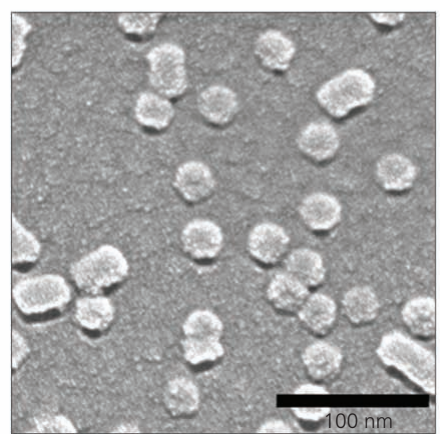

(f)

Figure 7. AFM topography images of a $4 \times 4$ nanopore array before $(a, b)$ and after $(c, d)$ the insertion of nanorings to serve as pore-inpore inlays. The images in (b) and (d) show the identical surface area as (a) and (c), respectively, but with a $z$-scale adopted to identify pores occupied by nanoparticles. The red circles represent those pores where complete or partial occupation by a nanoparticle is observed. (e) Zoom-in image of the pore in the black frame shown in (c). (f) SEM image of nanorings 
Improved manufacture of hybrid

membranes with bionanopore adapters

capable of self-luting

Altintoprak, Farajollahi, Seidenstücker et al. occupation by a nanoparticle is obvious. About half of the template pores came out to contain such inlays, although no extensive statistical analysis was possible due to the limited pore numbers in this type of SSM. Importantly, SSM templates treated with equally prepared buffer devoid of nanorings did not exhibit similarly filled pores (Figures 7(a) and 7(b)). Hence, the authors conclude that the nanoobjects inside the template pore channels indeed represent successfully integrated nucleoprotein rings. Figure 7(e) shows the zoom-in image of the pore in the black frame of Figure 7(c), as a representative example of an occupied pore. The particle marked with the white arrow exhibits an apparent diameter of $36 \mathrm{~nm}$, which is in agreement with the expectation that AFM tip convolution is taken into account: the recalculated diameter after deconvolution of the marked nanoparticle amounts to $18.6 \mathrm{~nm}$ (Figure S4 in the online supplementary material), which is in nice accordance with the diameter of $18 \mathrm{~nm}$ confirmed for the disks by SEM investigation (Figure 7(f)).

\subsection{Proof-of-principle insertion of DNA-decorated GNPs into porous SSM templates}

In all nanoring insertion experiments carried out so far with different SSM types (including studies by Farajollahi et $a l^{7}$ and Seidenstücker ${ }^{21}$ and this study), electrophoretic implantation was considerably more efficient than insertion by simple diffusion, but did never surpass values of about $60 \%$ of successfully combined pores in pores. To find out if enhanced negative charges of the bionanorings might promote their entrapping during electrophoresis-driven insertion, GNPs with a diameter of $20 \mathrm{~nm}$ were applied as model objects (Figure 8). The diameter of the GNPs corresponds to the nanoring diameter of $18 \mathrm{~nm}$. The GNPs' surfaces were coated with DNA-oligonucleotides (DNA-oligos), rendering them highly negative. For this purpose, 5'phosphorylated DNA-oligos 3 '-terminated by a thiol group were employed that undergo covalent thiolate-gold bonding, ${ }^{151}$ resulting in DNA-oligo-decorated GNPs (oligo-GNPs). The negatively charged phosphate backbones and the $5^{\prime}$-end-exposed

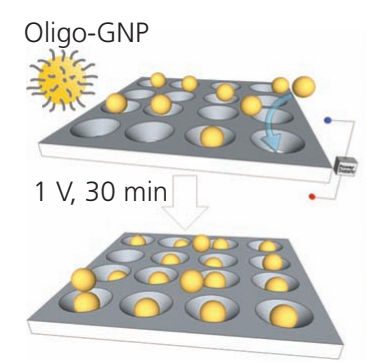

(a)

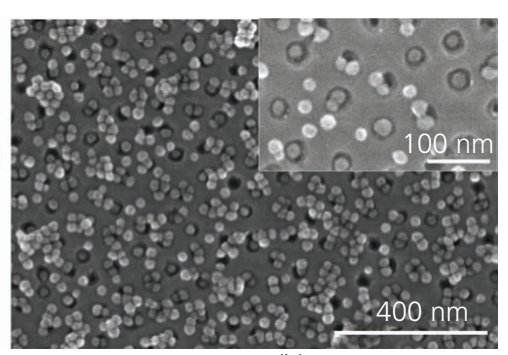

(b)
Figure 8. Toward high-efficiency loading of SSM pores by help of surface-exposed negative charges: (a) Electrophoresis-driven insertion of GNPs $20 \mathrm{~nm}$ dia. conjugated with DNAoligonucleotides (oligo-GNP) into SSM templates: experimental layout. (b) Top view SEM image of an SSM membrane with a majority of their conical pores with oligo-GNPs entrapped; overview and detail ${ }^{21}$

phosphate groups introduce a strong negative charge and hence also improve the colloidal stability of the oligo-GNPs. These were then subjected to electrophoresis-driven insertion into SSMs harboring millions of conical-shaped pores of $30 \mathrm{~nm}$ front-side and $11 \mathrm{~nm}$ back-side diameters, in analogy to previous experiments with TMV-based nanorings. SEM analysis of the membrane indicated that $90 \%$ of the SSM pores were occupied by oligo-GNPs (Figure 8(b)), a substantially increased percentage in relation to that obtained with the moderately negative nanodisks for this SSM type before. ${ }^{21}$ This suggests that a highly negative surface charge of nanoparticles might be advantageous for their efficient insertion into template pores with similar diameters, although it cannot be excluded that the spherical shape and the GNPs' density are important parameters in this context as well. Therefore, subsequent experiments on improving the pore-in-pore integration will need to compare nanoring preparations with distinct overall charge. As realized for the GNPs, this may also be modulated by way of accessory nucleic acids exposed on the bionanoparticles (to be published elsewhere).

\subsection{Gap sealing by bionic glue: biomineralization and its detection}

A mandatory step toward functional biohybrid membranes is an irreversible interconnection of the TMV-derived soft-matter pore adapters and the inorganic SSM templates. To avoid leakage, firm and continuous sealing of the annular gaps between the nanorings and the SSM pores is crucial. This technically challenging task might be accomplished best by means of an externally induced self-luting process - that is, by a biologically inspired, peptidenucleated deposition of a silica interlayer in situ (Figure 9). Hydrolyzed TEOS or tetramethoxysilane (TMOS) derivatives of low condensation degree (silanols or silicic acids) and thus size

Silica colloidal particles and three-dimensional networks

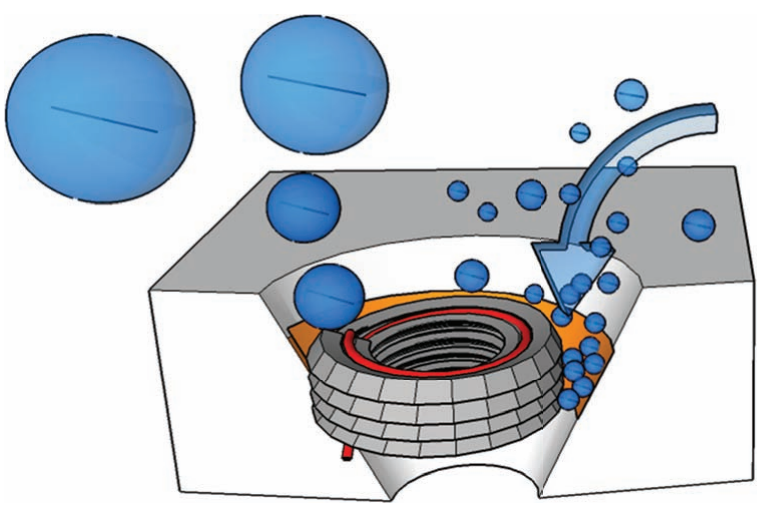

Figure 9. Concept of peptide-guided gap sealing by bionic 'silica glue'. Depending on the precursor preparation, differently sized silica aggregates may form, which are expected to hamper or promote silica deposition in a small confinement. Small precursors can be generated - for example, by acid-mediated hydrolysis of TMOS or TEOS. See the paper of Belton et al. ${ }^{110}$ for a mechanistic background 
are the most promising precursors, since they should be able to diffuse deeply into nanometer-sized clefts, where they would be converted into a bionic glue by appropriate silicificationmediating peptides installed on the outer nanoring rims.

High spatial selectivity of the process would be crucial to avoid silica formation inside the protein nanopore, retaining its specific permeability. An auspicious peptide sequence directing silica formation to the outer surface of both TMV nanorods ${ }^{8}$ and TMVderived nanorings ${ }^{20}$ has been identified during recent years in the authors' team: the peptide KD10 (i.e. $(\mathrm{KD})_{10} \mathrm{C}$ ) exerting a chargerelay effect $^{98}$ due to the repetitively alternating lysine-aspartic acid (KD) residues. It rendered tight control over the silicon oxide deposition kinetics by sol-gel condensation and thus the thickness of the mineral layer if an ethanolic TEOS precursor was applied (see Section 1 for more details). As, however, TMV nanorings did not withstand incubation in the ethanol-containing precursor ${ }^{20}$ and smaller silicic acid precursors have to be favored anyway to gain access to the nanometric gaps between nanoring rims and SSM template pores (Figure 9), the authors have systematically studied reaction conditions advantageous for a well-controlled self-luting process in situ. TMV nanorings were equipped with the peptide $\mathrm{KD} 10$ as described, ${ }^{20}$ and subsequent silicification tests were performed by use of silicic acid precursors freshly hydrolyzed from both TEOS and TMOS, respectively, since the size of the precursor complexes formed throughout subsequent reaction stages might differ between the products of those two compounds and thereby affect mineralization efficiencies in narrow gaps.

TEOS and TMOS were hydrolyzed in hydrochloric acid and applied in aqueous solution, according to previous bioinspired mineralization experiments with silica precipitation-inducing peptides ${ }^{95,97,139}$ or virus templates. ${ }^{138}$ Upon acid-mediated decomposition, the TEOS/ hydrochloric acid solution remained separated into two phases even after $15 \mathrm{~min}$ of shaking, while TMOS converted into silicic acids within $5 \mathrm{~min}$, as concluded from the vanished phase boundary. The different hydrolysis efficiencies may be attributed to the different polarities of the substrates' alkoxy groups, as a gradually decreasing polarity of these groups coincided with a decline of the alkoxysilanes' hydrolysis. ${ }^{152}$ On account of the incomplete conversion of TEOS, solely the aqueous phase containing an unknown silicic acid concentration was used as precursor for nanoring silicification from this educt. The TMOS-derived products were applied as prepared. To get a rough idea of the two precursors' silicic acid contents, the authors estimated their concentrations from published data. The aqueous phase of hydrolyzed TEOS contains around $1 \mathrm{mM}$ silicic acid at $\mathrm{pH} 6,{ }^{153}$ which was sufficient to mineralize hydrophilic Pegylated M13 bacteriophages, resulting in a reasonable silica shell formation as described. ${ }^{138}$ Referring to these data, the FC of silicic acid in the nanoring mineralization reaction employing TEOS-derived precursors was estimated to be around $0.3 \mathrm{mM}$, whereas those in TMOS-derived preparations was about $20 \mathrm{mM}$ (see Section 2). Consequently, the silicic acid concentration was below supersaturated conditions. Supersaturation of silicic acid in aqueous solution (around $1-2 \mathrm{mM}$ ) results in polymerization into silica. ${ }^{154}$ Silica shell formation was monitored by TEM analysis of the nanorings (Figure 10).

Upon use of TEOS-derived silicic acid precursors, samples were documented after $24 \mathrm{~h}$ and $4 \mathrm{~d}$, respectively. The reactions were carried out at $\mathrm{pH} 4.0$ in DD water combined with TEOS-derived silicic acid precursors and hydrochloric acid at $15^{\circ} \mathrm{C}$ to reduce the velocity of silica condensation ${ }^{109}$ and, furthermore, to minimize unspecific polymerization of the silicic acid. The mineralized nanoring-KD10, functionalized with the peptides, clearly shows a spatially specific accumulation of silica around its protein rim (Figure 10(a)), whereas unspecific precipitation of silica is detectable for the peptide-free biotemplates, nanoring-Lys and nanoring-polyethylene glycol (PEG), respectively (Figures 10(b) and $10(\mathrm{c})$ ). Longer reaction times induced higher contour contrast due to a higher degree of silica precipitation at the nanoring-KD10 rims (Figure 10(e)), whereas the appearance of both nanoring-Lys and nanoring-PEG remained unaffected after the longer exposure to silicic acid (Figures 10(f) and 10(g)). In the course of the ongoing silica precipitation, an increase in unspecific mineralization of the nanoring-KD10 sample was also observed, with electron-dense deposits covering the entire analyzed area of the copper grid after $4 \mathrm{~d}$ (Figure 10(e)). Since silica formation did not occur in the control reaction with all educts but DD water replacing the biotemplates (Figures 10(d) and 10(h)), the nanorings were assumed to be responsible for inducing polycondensation and silica precipitation. Based on the previously calculated silicic acid concentration $(0.3 \mathrm{mM})$, the results of nanoring mineralization indicate that they induced the silica precipitation in an undersaturated silicic acid solution. Although the silica-forming precursor TEOS thus exhibited appropriate performance, the exact concentration of the silicic acid educt is unknown, restricting concentration-dependent investigations of mineral precipitation. Additionally, under the conditions applied, nanoring-KD10 particles assembled into head-to-tail aggregates (Figure 10(a)). This was presumably induced by the hydrochloric acid in the reaction mixture, decreasing the $\mathrm{pH}$ from $5 \cdot 5$ to $4 \cdot 0$ and increasing the ionic strength from zero to $1.3 \times 10^{-7} \mathrm{M}$. Head-to-tail aggregation of TMV particles is known to be induced at low $\mathrm{pH}^{155,156}$ Furthermore, increasing ionic strength also enhances the polymerization of TMV CP independent of RNA templates. ${ }^{157,158}$ As a result, the short four-turn helices apparently were influenced in their aggregation behavior and assembled into particles of higher aspect ratio (Figures 10(a) and 10(e)). Furthermore, silicified nanoring-KD10 accumulated to small networks of several head-totail aggregates stuck together. Similar three-dimensional networks are commonly observed in the presence of salt, amines or basic amino acids at neutral and alkaline $\mathrm{pH}$ values. ${ }^{110}$ In contrast, nanorings devoid of peptides remained unaffected under these conditions. Such nanorings were scarcely detected by TEM analysis and were surrounded by unspecific silica precipitates, which might have impeded head-to-tail aggregation or accumulation.

Due to the inefficient hydrolysis of TEOS in hydrochloric acid and thus uncertain silicic acid concentration, the silicification 
Bioinspired, Biomimetic and Nanobiomaterials Volume 8 Issue BBN1
Improved manufacture of hybrid

membranes with bionanopore adapters

capable of self-luting

Altintoprak, Farajollahi, Seidenstücker et al.

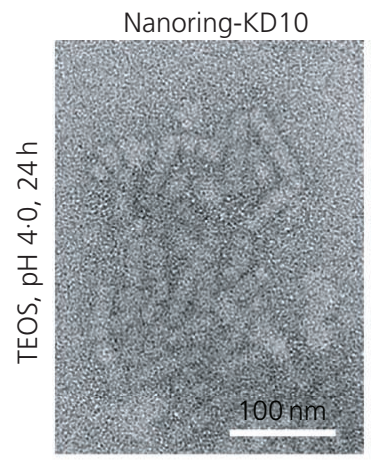

(a)

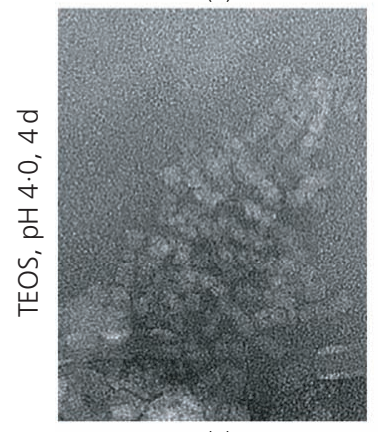

(e)

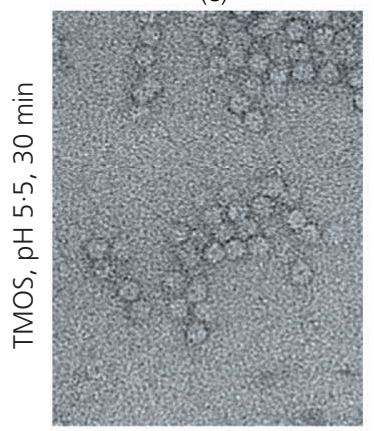

(i)

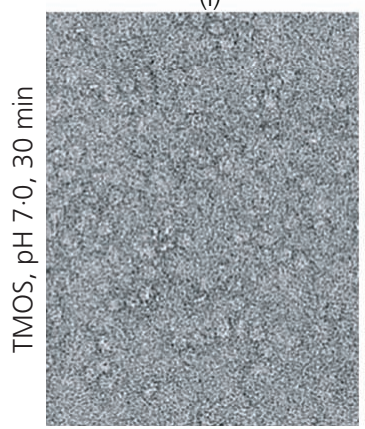

(m)

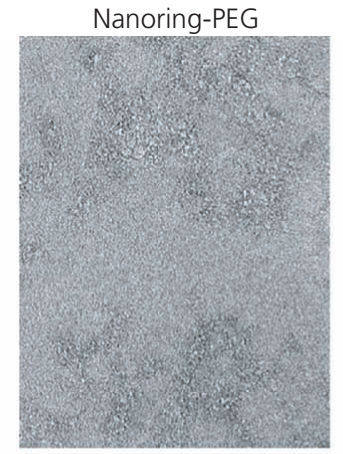

(b)

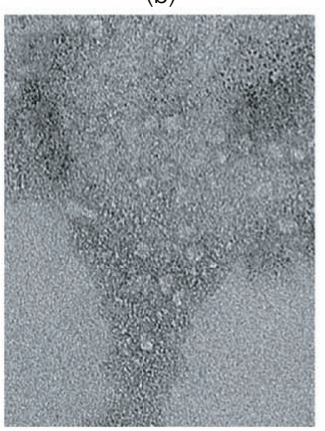

(f)

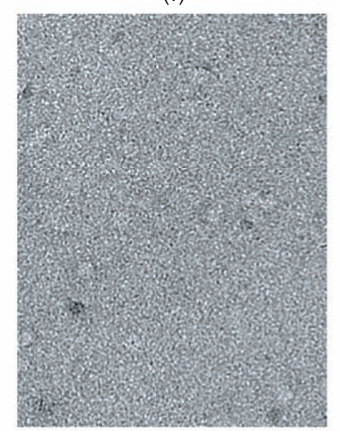

(j)

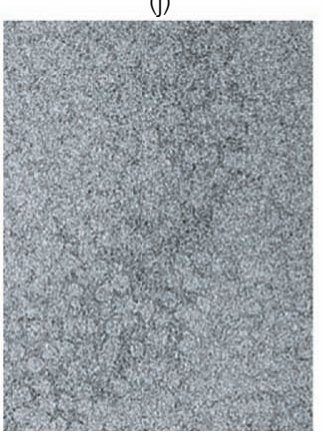

(n)

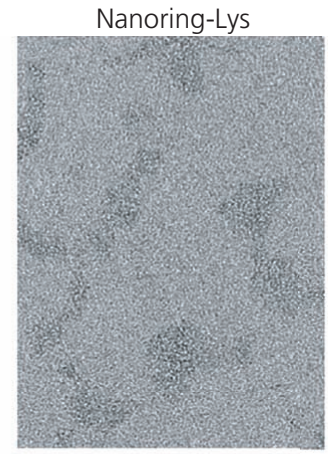

(c)

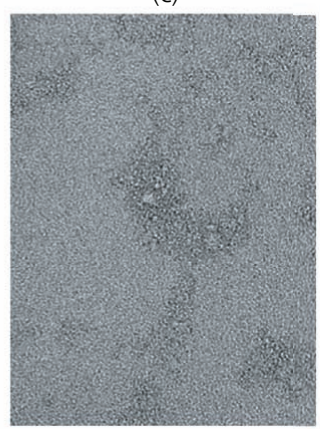

(g)

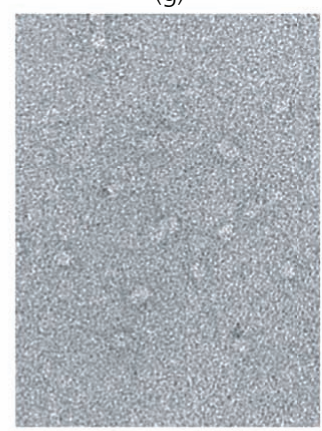

$(k)$

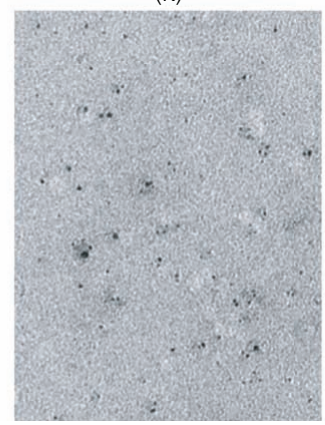

(o)

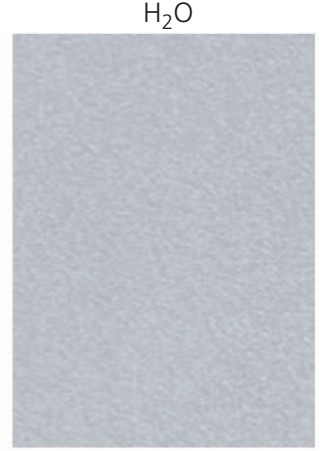

(d)

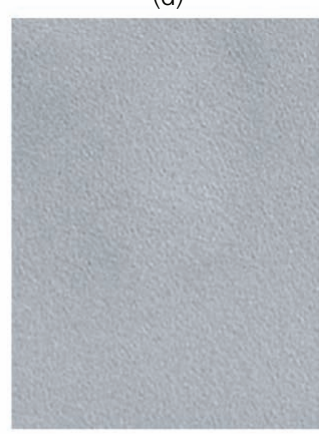

(h)

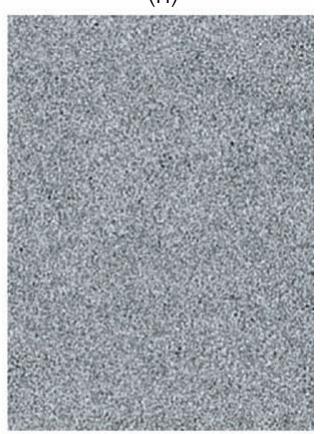

(I)

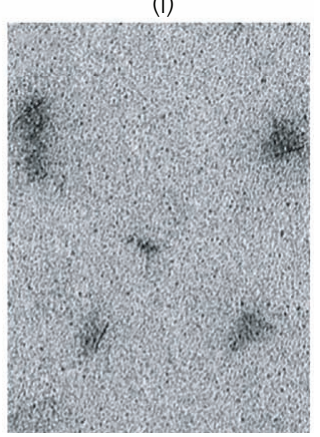

(p)

Figure 10. Comparative analysis of bioinspired mineralization at the outer rim of differently modified TMV-based nanorings under distinct conditions. TEM analysis of the different nanoring preparations (as indicated earlier) incubated with hydrolyzed TEOS of undefined silicic acid concentration at $\mathrm{pH} 4.0$ and $15^{\circ} \mathrm{C}(\mathrm{a}-\mathrm{d})$ after $24 \mathrm{~h}$ and (e-h) after $4 \mathrm{~d}$ and of nanorings combined with hydrolyzed TMOS, corresponding to $20 \mathrm{mM}$ silicic acid in an aqueous solution for $30 \mathrm{~min}$ at $23^{\circ} \mathrm{C}^{20}$ at $(\mathrm{i}-\mathrm{l}) \mathrm{pH} 5.5$ in DD water and $(\mathrm{m}-\mathrm{p}) \mathrm{pH} 7.0$ in $20 \mathrm{mM}$ Tris-hydrochloric acid. ' $\mathrm{H}_{2} \mathrm{O}$ ', control lacking a biotemplate (template fraction replaced by water in the reaction mixture); PEG, polyethylene glycol. Scale bar refers to all images. See text for details 
efficiency at two different $\mathrm{pH}$ values was examined using hydrolyzed TMOS as precursor. According to the literature, silicic acid condensates faster at neutral or alkaline $\mathrm{pH}$ and forms particles with increased diameter in comparison to low $\mathrm{pH}$ values. ${ }^{110}$ To obtain clearly distinguishable effects, a slightly acidic $\mathrm{pH}$ at 5.5 in carbon dioxide-saturated DD water and neutral conditions at pH 7.0 in $20 \mathrm{mM}$ Tris-hydrochloric acid buffer were selected. Furthermore, the temperature was increased to enhance the silica precipitation velocity, ${ }^{109}$ and the reaction time was reduced to prevent the accumulation of unspecific large silica particles. The silicification reaction was executed for $30 \mathrm{~min}$ at $23^{\circ} \mathrm{C}$, and mineral precipitation on the nanoring rims was studied by TEM analysis (Figures 10(i)-10(p)). At $\mathrm{pH} 5 \cdot 5$, the precipitation of a thin electron-dense layer of silica around the nanoring-KD10 rims was induced. The controls nanoring-Lys and nanoring-PEG were scarcely detectable by electron density contrast (Figures 10(i) and 10(k)), indicating that the peptide improved and guided the silica precipitation under these conditions. Similar to the agglomeration of nanoring-KD10 particles upon incubation with prehydrolyzed TEOS (Figure 10(a)), the nanorings silicified from hydrolyzed TMOS at $\mathrm{pH} 5.5$ accumulated locally and attached side by side in a monolayer covering the carbon film (Figure 10(i)). However, compared to nanoring mineralization reactions with TEOS-derived silicic acids, no head-to-tail aggregation was detectable. As described earlier, decreasing $\mathrm{pH}$ and increasing ionic strength induce the polymerization of the TMV CP. Because of the different hydrochloric acid concentrations in the reaction mixtures, the ionic strength (in relation to chloride $\left(\mathrm{Cl}^{-}\right)$ions) as well as the $\mathrm{pH}$ value of the silicification solution differed: $1.3 \times 10^{-7} \mathrm{M}$ at $\mathrm{pH}$ $4 \cdot 0$ (TEOS) and $8 \cdot 5 \times 10^{-9} \mathrm{M}$ at $\mathrm{pH} 5 \cdot 5$ (TMOS), respectively. Thus, the calculated ionic strength of the reaction with hydrolyzed TMOS was by a factor of $15 \cdot 3$ smaller than with hydrolyzed TEOS, which favored the dispersion of the nucleoprotein nanorings. These findings resemble those of earlier systematic analyses on TMV CP or nanotube polymerization: a tenfold decrease in ionic strength induced depolymerization of TMV CP aggregates at $\mathrm{pH} 7 \cdot 5,^{158}$ whereas at $\mathrm{pH} 6 \cdot 5$, head-to-tail aggregation of TMV tubes occurred after increasing the salt concentration (APS) of a TMV-aniline solution. ${ }^{159}$ To the authors' knowledge, for the assembly and disassembly at $\mathrm{pH} 5 \cdot 5$, comparable data are not available in the literature. Conclusively and in fundamental agreement with previous studies, RNAstabilized four-turn helices retained their structure at low $\mathrm{pH}$ in the absence of salt, without undergoing head-to-tail aggregation during silica sheathing from hydrolyzed TMOS precursors. After mineralization reactions at neutral $\mathrm{pH} 7 \cdot 0$, however, the TEM analysis of silica precipitation from hydrolyzed TMOS indicated mainly unspecific condensation for both nanoring-KD10 and nanoring-Lys templates, resulting in a silica layer that covered the carbon film or granular structures, respectively (Figures 10(m)$10(\mathrm{p})$ ). Although with increasing $\mathrm{pH}$ a higher silica condensation rate is expected, and has also been observed in this study (see e.g. 'Nanoring-Lys' and ' $\mathrm{H}_{2} \mathrm{O}$ ' in Figures $10(\mathrm{n})-10(\mathrm{p})$ ), silica formation at $\mathrm{pH} 7 \cdot 0$ was not site-specifically directed to the outer functionalized nanoring rim if compared to the results of nanoring-KD10 at $\mathrm{pH} 4 \cdot 0$ or $5 \cdot 5$, using prehydrolyzed TEOS or TMOS, respectively (Figures 10(a) and 10(i)).

Taken together, the silicification experiments carried out with the peptide $(\mathrm{KD}){ }_{10} \mathrm{C}$ and hydrolyzed TMOS at different $\mathrm{pH}$ values $(5 \cdot 5$ and $7 \cdot 0)$ in the presence of equal amounts of silicic acid $(20 \mathrm{mM})$ indicate that spatially specific silica accumulation was favored at low $\mathrm{pH}$. This is different from polylysine-induced silica condensation, which shows optimal polymerization in a $\mathrm{pH}$ range of $7 \cdot 2-9 \cdot 2$ promoting the interaction of polylysine with the negatively charged silicic acid and also different from the effect of polyaspartate, which exhibits a slight catalytic activity at $\mathrm{pH} 4.9$, where neutral silicic acid is the predominant form. ${ }^{160}$ As silicic acid is supposed to exist in its protonated state at low $\mathrm{pH}$, its interaction possibility with positively charged amino acid residues is generally reduced under acidic conditions. ${ }^{109}$ For the peptide $(\mathrm{KD})_{10} \mathrm{C}$, a positive net charge $(0.7)$ is calculated for $\mathrm{pH} 5.5$ and a slightly negative charge $(-0 \cdot 1)$ at $\mathrm{pH} 7 \cdot 0 .{ }^{161}$ Hence, at $\mathrm{pH} 5 \cdot 5$, more than half of the peptides' amino acids are protonated. Thus, the sitespecific mineralization of nanoring-KD10 at $\mathrm{pH} 5 \cdot 5$ could be induced by different mechanisms. According to literature data, negatively charged silica surfaces interact weakly with polar amino acid residues such as serine or histidine as well as with the acidic aspartic acid, forming hydrogen bonds, whereas they interact strongly with protonated lysine. ${ }^{162}$ As the isoelectric point of silicic acid is around $\mathrm{pH} 2,{ }^{163}$ silicate molecules are partially deprotonated at higher $\mathrm{pH}$ values. Thus, silicic acid might be attracted by aspartic acid as well as by lysine due to polar and ionic interactions, respectively. Hence, it could, theoretically, be favorable to select conditions causing an overall rather positive net charge at the nanoring rim, to induce silica precipitation. However, silica deposition was not detected on the outer surface of the bare nanoring-Lys that exposes positively charged lysine residues. Hence the spatially selective silica precipitation around the nanoring-KD10 under unfavorable conditions at $\mathrm{pH} 5 \cdot 5$ depended on the chargerelay mechanism of the peptide $(\mathrm{KD})_{10} \mathrm{C}$ installed on the outer protein rim, displaying repetitively alternating amino and carboxyl groups ${ }^{98}$ rather than a positive net charge. From this point of view, the mineralization process of the peptide $(\mathrm{KD})_{10} \mathrm{C}$ at $\mathrm{pH} 5.5 \mathrm{might}$ be related to the enzymatically governed silica condensation at the active site of silicatein ${ }^{107}$ and thus biological catalysis. Due to the close proximity of protonated amino and negatively charged carboxyl groups under acidic conditions, intramolecular hydrogen bond formation between these side-chains might be possible, resulting in positive or negative partial charges, respectively. In this model, similar to the interplay between histidine and serine of the silicatein active site, the silicon atom of silicic acid can be immobilized by nucleophilic attack of the partially negatively charged oxygen atom of the aspartic acid carboxyl group, in combination with a proton transfer from the lysine amino group and a subsequent water molecule release. Thereafter, polymerization is induced by a nucleophilic attack of the $\mathrm{OH}$ group of the covalently bound silicic acid at a second orthosilicic acid molecule. The main advantage of such a charge-relay mechanism 
for spatially selective mineral formation is reduced unspecific condensation of silica precursors, which possibly occurs under neutral and basic $\mathrm{pH}$ or in the presence of catalysts such as ammonium hydroxide $\left(\mathrm{NH}_{4} \mathrm{OH}\right) .{ }^{164}$ In summary, the charge-relay effect is stronger pronounced under acidic than neutral conditions, presumably due to the proton transfer of the slightly positive peptides, driving the condensation of silicic acids into silica.

The convincingly controlled sol-gel reaction directed by the peptide-fashioned nanoring-KD10 in the presence of silicic acid precursors freshly hydrolyzed from TMOS at $\mathrm{pH} 5.5$ now remains to be transferred to the spatially confined pore-in-pore environment of the composite membrane, to scrutinize whether it enables a durable and leak-proof interconnection of the soft- and hard-matter components. Of greatest promise is the authors' further finding that most likely, the central protein pores of the nanorings appeared free of silica deposits in most cases, within the limits of the TEM analysis. The newly developed protocol thus is likely to fulfill all prerequisites to establish highly selective, nanometrically tunable junctions at bioinorganic interfaces in future hybrid devices.

\subsection{Biomimetic nanopores with modifiable inner channel and/or a singular docking site for effector units}

To tailor the selective permeability of the nucleoprotein pore adapters and to expand their accessibility to chemical modifications, nanoring building blocks were engineered at the protein as well as at the nucleic acid level. First, this led to nanopores with altered surface charge, and second, this introduced functional groups enabling an immobilization of small reactive molecules or enzymes. Modifications of CP domains exposed inside the nanopore channels may simply reduce the nanopore diameters' below $4 \mathrm{~nm}$ or alter their hydrophilicity. Appropriate molecules could be short fatty acids, mono- or di-saccharides or cyanine dyes with a hydrodynamic radius up to about $1.5 \mathrm{~nm}$, applied with moderate coupling rates to fit the molecules into the central nanoring cavity. Additional functionality such as switchable gating or even enzymatic molecule conversion during passage of accordingly modified pore adapters might be best achieved by addressing one end of the scaffold RNA (see later). At the protein level, two mutant CPs were generated by site-directed mutagenesis of a plant-infectious TMV clone, ${ }^{12}$ thereby allowing fast and efficient harvesting of the modified $\mathrm{CP}$ species from leaves. For this purpose, nucleic acid triplets originally encoding glutamine (Gln, Q) or asparagine (Asn, N) were altered, which determine amino acids located near or inside the inner channel of the TMV capsid at positions Q99 and N101 in the WT protein sequence (Figure 11(a)). In separate TMV clones, either of them was replaced by lysine (Lys, K) with a primary amine in its side-chain. This is addressable by simple succinimidyl (NHS) estermediated conjugation reagents and thus allows coupling molecules close to the central pore, with up to 68 binding sites available if all CPs per nanoring were of the Q99 or N101 type. Thereby, considerable changes of the physicochemical properties are possible. In addition, the modified nanopores are more positively charged than those of the original $\mathrm{CP}$ species. The respective nucleotide exchanges were confirmed for both TMV-CP mutants (Figure S5(a) in the online supplementary material), which are referred to in the following as $\mathrm{TMV}-\mathrm{CP}_{\mathrm{Q} 99 \mathrm{~K}}$ and $\mathrm{TMV}-\mathrm{CP}_{\mathrm{N} 101 \mathrm{~K}}$. Both TMV variants were able to infect tobacco plants ( $N$. tabacum) systemically. Symptoms occurred delayed in the case of $\mathrm{TMV}^{-\mathrm{CP}_{\mathrm{N} 101 \mathrm{~K}}}(13 \mathrm{dpi})$, whereas for TMV-CP ${ }_{\mathrm{Q} 99 \mathrm{~K}}$, they appeared at $10 \mathrm{dpi}$ similar to WT TMV. Newly infected leaves displayed typical mosaic patterns (Figure 11(b)), with the symptoms of $\mathrm{TMV}_{\mathrm{Q} 99 \mathrm{~K}}$ more severe than those of $\mathrm{TMV}_{\mathrm{N} 101 \mathrm{~K}}$. For further investigations, the mutated TMV particles were isolated according to a standard protocol ${ }^{141}$ which was developed for WT TMV particles $\left(\mathrm{TMV}_{\mathrm{wt}}\right)$. Under these conditions, $\approx 0.3 \mathrm{mg}$ TMV-CP ${ }_{\mathrm{Q} 99 \mathrm{~K}}$ and $\approx 1.5 \mathrm{mg}$ TMV-CP ${ }_{\mathrm{N} 101 \mathrm{~K}}$ per gram leaf material was yielded with $260 \mathrm{~nm} / 280 \mathrm{~nm}$ UV absorption ratios of 1.25 and 1.21 , respectively. These results are in the same range as shown for $\mathrm{TMV}_{\mathrm{wt}}{ }^{141,150}$ The apparent length of the TMV particles analyzed by TEM differed from that of $\mathrm{TMV}_{\mathrm{wt}}$ particles $(300 \mathrm{~nm})$ in the case of the TMV-CP $\mathrm{N}_{\mathrm{N} 101 \mathrm{~K}}$. The measured average length of this mutant was around $110 \pm 73 \mathrm{~nm}$ with a median of $95 \mathrm{~nm}$ (Figure S6 in the online supplementary material), due to broken fragments of the virions (Figure 11(c)). The average length of $\mathrm{TMV}_{\mathrm{Q} 99 \mathrm{~K}}$ was in agreement with the $\mathrm{TMV}_{\mathrm{wt}}$ length of $308 \pm$ $189 \mathrm{~nm}$ and a median of $281 \mathrm{~nm}$ (Figures 11(d) and S6 in the online supplementary material). Similar CP mutants of the related tomato mosaic virus (ToMV) were published previously by Kobayashi et al., ${ }^{165}$ but interestingly with different effects on the virus particles. The ToMV mutant S101K with a comparable amino acid exchange at the same position as that of $\mathrm{TMV}_{\mathrm{N} 101 \mathrm{~K}}$ exhibited a length corresponding to that of the WT ToMV of $300 \mathrm{~nm}$. Although the in silico alignment ${ }^{166}$ of various CPs of TMV-related viruses (tobamoviruses) suggests that this position is amenable to a flexible amino acid exchange (Figure S5(b) in the online supplementary material) and although the mutant was capable of infecting plants systemically, the TEM analysis of $\mathrm{TMV}_{\mathrm{N} 101 \mathrm{~K}}$ indicates that the additional positive charge at position 101 of the amino acid sequence impaired the assembly, which was observed neither for $\mathrm{TMV}_{\mathrm{Q} 99 \mathrm{~K}}$ nor for the ToMV mutant S101K.

To test whether the newly inserted lysine residues are amenable to chemical coupling, an NHS-functionalized fluorophore (Atto 488NHS) was reacted with the TMV particles and both educts and products were analyzed by SDS-PAGE, in comparison to equally treated $\mathrm{CP}_{\mathrm{wt}}$. Although the $\mathrm{CPs}$ are all of same size $(17 \cdot 5 \mathrm{kDa}),{ }^{167}$ the electrophoretic mobility of the mutant proteins was altered (Figure 11(e)). The additional positive charge after lysine introduction might lead to a higher accumulation of negatively charged dodecyl sulfate molecules, enhancing the electrophoretic mobility of the inner channel mutants. After chemical modification, only TMV-CP ${ }_{\mathrm{N} 101 \mathrm{~K}}$ was strongly labeled with the fluorescent dye, whereas for $\mathrm{TMV}_{-} \mathrm{CP}_{\mathrm{Q} 99 \mathrm{~K}}$ and for $\mathrm{TMV}-\mathrm{CP}_{\mathrm{wt}}$, only a weak and no signal, respectively, were detectable (Figure 11(f)). This selective labeling of the TMV-CP $\mathrm{N}_{\mathrm{N} 101 \mathrm{~K}}$ is probably due to the position of the new lysine, which is less embedded in the tertiary and quaternary structures of the $\mathrm{CP}$ assembly than the naturally existing lysine residues at positions $\mathrm{K} 53$ and $\mathrm{K} 68$, and the engineered lysine of the 
Bioinspired, Biomimetic and Nanobiomaterials Volume 8 Issue BBN1
Improved manufacture of hybrid membranes with bionanopore adapters capable of self-luting

Altintoprak, Farajollahi, Seidenstücker et al.
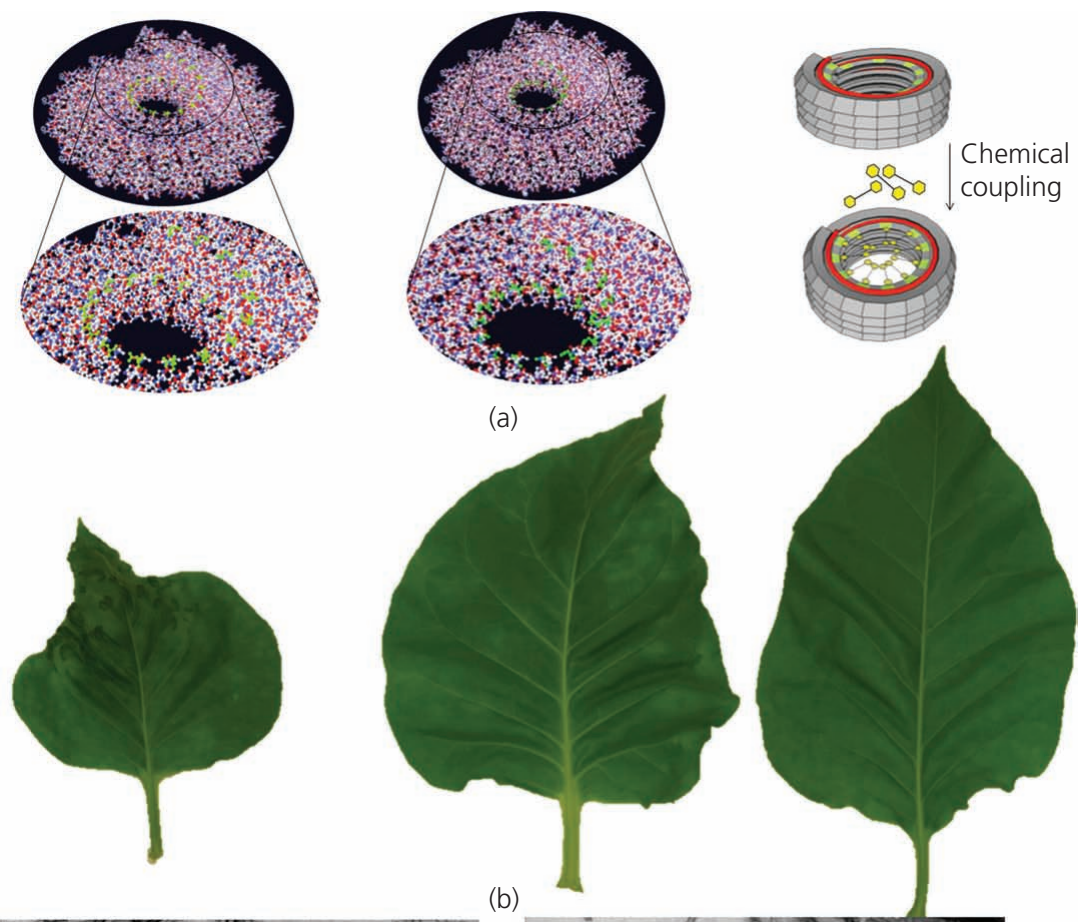

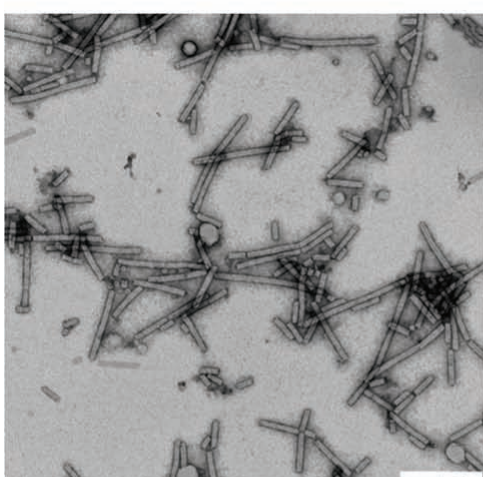

(c)

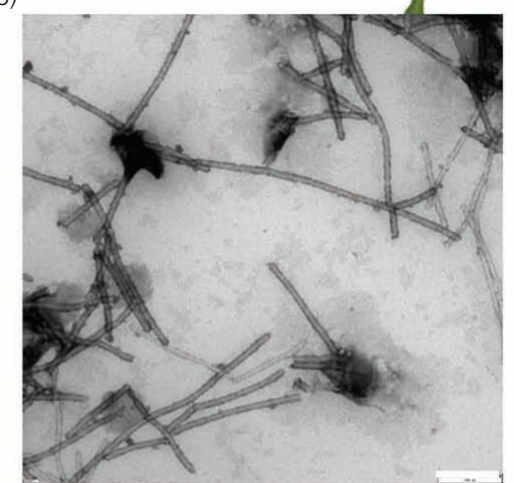

(d)

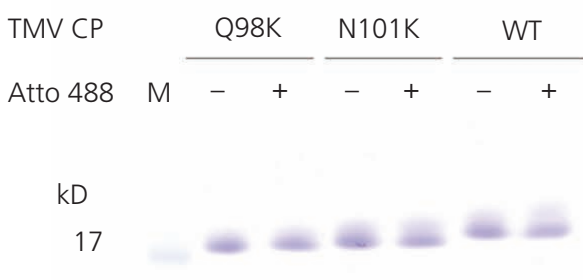

(e)

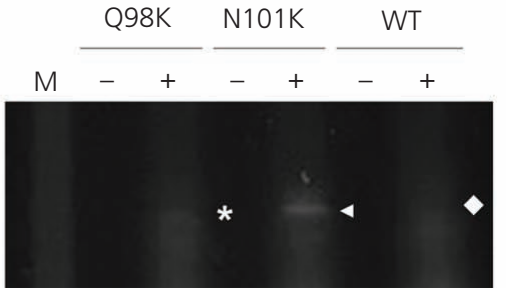

(f)

Figure 11. TMV inner channel-affecting CP mutants for chemical functionalization through CP moieties. (a) Quaternary structure of the CP with indicated amino acids selected for exchange into lysine (K) at positions Q99 and N101. (b) N. tabacum leaves infected by $\mathrm{TMV}_{\mathrm{Q} 99 \mathrm{~K}}$ (left) or $\mathrm{TMV}_{\mathrm{N} 101 \mathrm{~K}}$ (middle) compared to an uninfected leaf (right). TEM images of isolated (c) $\mathrm{TMV}_{\mathrm{Q} 99 \mathrm{~K}}$ and (d) $\mathrm{TMV}_{\mathrm{N} 101 \mathrm{~K}}$ particles (scale bar: $200 \mathrm{~nm}$ ). (e, f) SDS-PAGE of TMV CPs labeled with Atto 488 through NHS ester coupling; (e) proteins in the gel are stained with Coomassie Brilliant Blue R-250; (f) Atto 488-labeled proteins are visualized by UV light. The fluorescent signal of CPN101K (arrowhead) shows highest intensity compared to $\mathrm{CPQ}_{99 k}$ (asterisk) and $\mathrm{CP}_{\mathrm{wt}}$ (diamond). See Section 2 for further details

mutant TMV-CP ${ }_{\mathrm{Q} 99 \mathrm{~K}}$. However, as the additional lysine of the TMV$\mathrm{CP}_{\mathrm{Q} 99 \mathrm{~K}}$ is at the convex side ${ }^{168}$ of the nanoring's end surfaces, around 16-17 primary amines of one CP turn should be available per nanoring for chemical modifications. In summary, two mutants were genetically engineered providing additional primary amines in the case of the TMV-CP $\mathrm{N}_{\mathrm{N} 101 \mathrm{~K}}$ inside the inner channel and around 16 primary amines in the case of the TMV-CP ${ }_{\mathrm{Q} 99 \mathrm{~K}}$ per particle at the convex end surface. Both mutants provide multivalent modifications 
and allow coupling of several molecules per TMV-based nanoring particle.

A second strategy for obtaining novel functionalities in close vicinity to the inner pore channel, but 'on top' of or below the nanoring's end faces, is modification of the RNAs' ends. The radius of the RNA-binding groove inside the CP helix is $4 \mathrm{~nm}$, and both RNA ends are accessible at the nucleoprotein particles' terminal faces to some extent. ${ }^{169}$ This strategy might put optional effector molecules a bit off the center of the inner channel and prevent its closure. To introduce singular anchor molecules into the viral nanorings that way, the RNA $5^{\prime}$ end was modified in a two-step reaction process, as realized for two scaffold RNAs of different lengths: 204 and $500 \mathrm{nt}$ (for details, see Section 2). First, the RNA $5^{\prime}$ phosphate group was enzymatically removed and a thiophosphate group was installed instead. The thiol at the $5^{\prime}$ end is then available for chemical coupling through Michael addition for example, by use of maleimide-functionalized molecules. In this work, a biotin-(PEG) $)_{11}-$ maleimide linker was tested to label the $5^{\prime}$ thiophosphate of the RNA by a potent bioaffinity anchor. After biotin conjugation, the RNAs were analyzed by urea PAGE followed by blotting the RNAs onto a membrane and detecting the biotin through a SAP conjugate (Figure 12). Strong signals of alkaline phosphatase reactivity were detectable for both modified RNAs, although it was not possible to determine the ratio of biotin-labeled to unmodified RNAs. Hence, to investigate if biotin-labeled RNA can be encapsidated inside $\mathrm{TMV}_{\mathrm{wt}} \mathrm{CPs}$, both components were mixed to start the assembly process and analyzed stepwise to characterize the structures formed. Native gel electrophoresis evidenced that disks were formed (Figure 12(a)), but could not provide information about the type of RNA packaged - biotin-labeled or residual unmodified RNA. To find out if $\mathrm{CP}$ rings were indeed scaffolded by biotin-modified RNAs, the assemblies were subjected to an RNase A protection assay, which indicates whether RNAs are protected by CPs against degradation during RNase treatment. The fraction of protected RNAs was analyzed by urea PAGE and RNA blotting, as described earlier (Figure 12). The signals of both RNase A-treated RNA types show negligible differences from the untreated RNAs after SYBR Gold staining only (Figure 12(b)). This indicates that they were protected against RNase A-mediated degradation and that nearly the total amount of input RNA in the assembly reaction was efficiently encapsidated by CPs. The blot further confirms that also the biotin-labeled RNA is protected against degradation (Figure 12(c)). This shows for the first time that it is possible to modify the $5^{\prime}$ end of a TMV scaffold RNA by a bioaffinity anchor molecule without impairing its assembly competence, which will allow monovalent modification at the concave ${ }^{168,170}$ end of the resulting TMV-like particles or nanoring structures.

\section{Conclusion}

A series of novel developments has advanced a recently proposed, unprecedented concept for the fabrication of robust, freestanding biohybrid nanoporous devices. Biomolecular, plant-virus-derived pore-in-pore inlays with central $4 \mathrm{~nm}$ protein channels offer manifold opportunities for implementing size-, charge- and

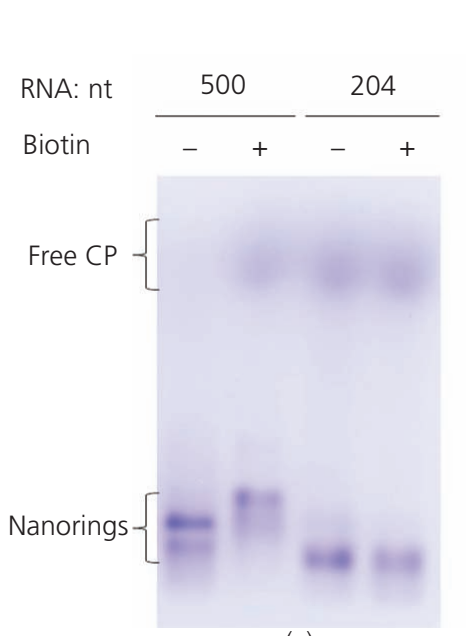

(a)

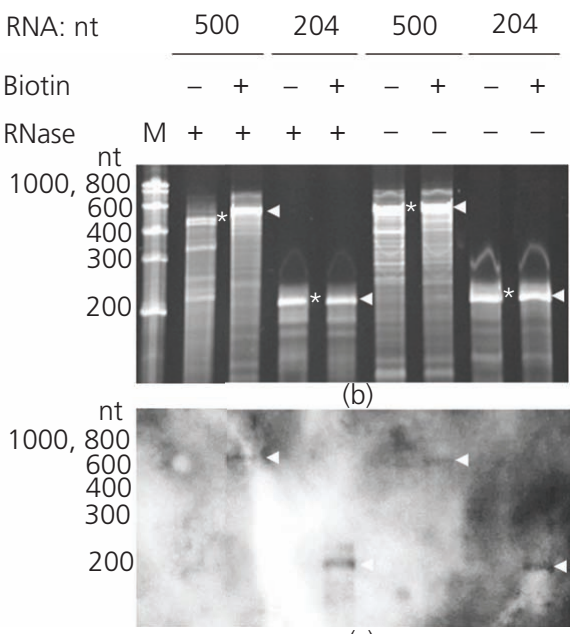

(c)

Figure 12. Site-specific functionalization of RNA-scaffolded CP assemblies (short TMV-like particles or nanorings) through the RNA $5^{\prime}$ ends, resulting in a singular docking site on one end of the particle, adjacent to the pore channel. (a) Native agarose gel electrophoresis of CP assemblies obtained with terminally modified RNA scaffolds (500 and 204 nt OA-containing RNAs, either 5'-terminally biotinylated (biotin) through a thiol-Michael addition CLICK reaction (+) or not (-)). Short viruslike particles or nanorings $(\approx 18 \mathrm{~nm} \times 18 \mathrm{~nm}$ and $\approx 9 \mathrm{~nm} \times 18 \mathrm{~nm}$ products for RNAs of 500 or $204 \mathrm{nt}$ length, respectively) show higher electrophoretic mobility than free CP, due to a higher negative charge conveyed by the RNA. (b, c) Analysis of the encapsidated RNA. (b) RNase protection assay of the RNA from intact assemblies, comparison of unmodified (asterisk) and biotin-modified (arrowhead) RNAs after RNase A treatment and subsequent release from the particles, as evaluated by urea PAGE and (c) biotin-specific streptavidin affinity analysis on blots. An efficient encapsidation of biotin-modified RNA into TMV CPs is evidenced by corresponding bands (arrowheads). For more details, refer to the text 
Bioinspired, Biomimetic and Nanobiomaterials Volume 8 Issue BBN1
Improved manufacture of hybrid

membranes with bionanopore adapters

capable of self-luting

Altintoprak, Farajollahi, Seidenstücker et al. structure-selective target discrimination capacities for biodetection and sorting tasks. A set of TMV-deduced building blocks enabling an easy installation of permeability-modulating molecules has been generated, with its protein building blocks accessible by farming in plants. Biochemically biotinfunctionalized scaffold RNAs, furthermore, permit the display of a single anchor site for streptavidin-conjugated molecules per nanoring, which can be employed for the immobilization of enzymes or other macromolecular effectors and may lead to more complex nanoarchitectures, including nanoporous derivatives with additional substrate transformation abilities such as employed, for example, in DNA nanopore sequencing approaches. Concomitantly, the encapsidation of a bioaffinity hapten-modified RNA in TMV CP has been demonstrated for the first time. The versatile bionanopore assemblies have also been shown to offer best prospects for their durable and intimate interlinkage with inorganic template pores by way of a bioinspired self-luting process: if equipped with appropriate peptides on the outer nanoring rims, they guided the deposition of nanometric silica sheaths from small silicic acid precursor sols reliably. This has been extensively optimized in this study to meet the conditions necessary for an externally induced immobilization and sealing process in situ, within the SSM template holes. In conclusion, the heteromultivalent RNA-scaffolded nanorings exhibit a unique combination of features demanded for the construction of biohybrid arrangements with complex functionality. They could be efficiently implanted into different types of freestanding SSMs, with electrophoretic insertion being superior to diffusion-based methods. To serve as readily available and predictably addressable counterparts of the bionanopores, novel types of inorganic membrane templates were fabricated by helium ion beammediated top-down drilling. Commercially available SN substrates could be transformed into arrays of predictably arranged and nanosized pore frames, which may enable functional investigations of distinct bionanopore species in parallel experiments and even single pore-analytical setups.

\section{Acknowledgements}

The authors would like to thank Cornelia Kocher for providing protocols and technical support for the TEM analysis, Professor Dr. S. Nussberger and PD Dr. M. Schweikert for granting access to the TEM, Gabriele Kepp for supporting fluorescence microscopy, Sigrid Kober for the preparation of TMV particles from tobacco plants and Diether Gotthardt for taking care of the tobacco plants. The authors thank Dr. Carlos Azucena for ITC-silane preparation and design of images. The authors also extend many thanks to Professor Dr. Holger Jeske for continuous support and constructive discussions of the project. They are grateful for the financial support of DFG SPP1569 (DFG-WE-4220/2-1 to 3, DFG-GL-709/ 1-3, DFG-ZI 317/28-1, DFG-PL 309/1-2, DFG-MA 1297/13-2).

\section{REFERENCES}

1. Schmidt J (2016) Membrane platforms for biological nanopore sensing and sequencing. Current Opinion in Biotechnology 39: 17-27.
2. Cao C and Long YT (2018) Biological nanopores: confined spaces for electrochemical single-molecule analysis. Accounts of Chemical Research 51(2): 331-341.

3. Wang S, Zhao Z, Haque F and Guo P (2018) Engineering of protein nanopores for sequencing, chemical or protein sensing and disease diagnosis. Current Opinion in Biotechnology 51: 80-89.

4. Howorka S (2017) Building membrane nanopores. Nature Nanotechnology 12(7): 619-630.

5. Seidenstücker A, Beirle S, Enderle F et al. (2018) Nanoporous silicon nitride-based membranes of controlled pore size, shape and areal density: fabrication as well as electrophoretic and molecular filtering characterization. Beilstein Journal of Nanotechnology $\mathbf{9}$ 1390-1398.

6. Altintoprak K, Seidenstücker A, Krolla-Sidenstein P et al. (2017) RNA-stabilized protein nanorings: high-precision adapters for biohybrid design. Bioinspired, Biomimetic and Nanobiomaterials 6(4): 208-223, https://doi.org/10.1680/jbibn.16.00047.

7. Farajollahi F, Altintoprak K, Seidenstücker A et al. (2018) Electrochemically driven insertion of biological nanodiscs into solid state membrane pores as a basis for 'pore-in-pore' membranes. Nanomaterials 8(4): 237.

8. Altintoprak K, Seidenstücker A, Welle A et al. (2015) Peptideequipped tobacco mosaic virus templates for selective and controllable biomineral deposition. Beilstein Journal of Nanotechnology 6: 1399-1412.

9. Bäcker M, Koch C, Eiben S et al. (2017) Tobacco mosaic virus as enzyme nanocarrier for electrochemical biosensors. Sensors and Actuators B: Chemical 238: 716-722.

10. Eiben S, Stitz N, Eber F et al. (2014) Tailoring the surface properties of tobacco mosaic virions by the integration of bacterially expressed mutant coat protein. Virus Research 180: 92-96.

11. Geiger FC, Eber FJ, Eiben S et al. (2013) TMV nanorods with programmed longitudinal domains of differently addressable coat proteins. Nanoscale 5(9): 3808-3816.

12. Kadri A, Maiss E, Amsharov N et al. (2011) Engineered tobacco mosaic virus mutants with distinct physical characteristics in planta and enhanced metallization properties. Virus Research 157(1): 35-46.

13. Koch C, Wabbel K, Eber FJ et al. (2015) Modified TMV particles as beneficial scaffolds to present sensor enzymes. Frontiers in Plant Science 6: 1137.

14. Schneider A, Eber FJ, Wenz N et al. (2016) Dynamic DNAcontrolled 'stop-and-go' assembly of well-defined protein domains on RNA-scaffolded TMV-like nanotubes. Nanoscale 8(47): 19853-19866.

15. Zang F, Gerasopoulos K, Brown AD, Culver JN and Ghodssi R (2017) Capillary microfluidics-assembled virus-like particle bionanoreceptor interfaces for label-free biosensing. ACS Applied Materials \& Interfaces 9(10): 8471-8479.

16. Fan $X Z$, Naves $L$, Siwak NP et al. (2015) Integration of genetically modified virus-like-particles with an optical resonator for selective bio-detection. Nanotechnology 26(20): 205501.

17. Zhou K, Zhang J and Wang Q (2015) Site-selective nucleation and controlled growth of gold nanostructures in tobacco mosaic virus nanotubulars. Small 11(21): 2505-2509.

18. Hou C, Luo Q, Liu J et al. (2012) Construction of GPx active centers on natural protein nanodisk/nanotube: a new way to develop artificial nanoenzyme. ACS Nano 6(10): 8692-8701.

19. Dedeo MT, Duderstadt KE, Berger JM and Francis MB (2010) Nanoscale protein assemblies from a circular permutant of the tobacco mosaic virus. Nano Letters 10(1): 181-186.

20. Lemloh ML, Altintoprak K, Wege C, Weiss IM and Rothenstein D (2017) Biogenic and synthetic peptides with oppositely charged amino acids as binding sites for mineralization. Materials 10(2): 119.

21. Seidenstücker A (2015) Physikalische Voraussetzungen für die Realisierung einer bio-anorganischen Hybridmembran mit 
Bioinspired, Biomimetic and Nanobiomaterials Volume 8 Issue BBN1
Improved manufacture of hybrid membranes with bionanopore adapters capable of self-luting

Altintoprak, Farajollahi, Seidenstücker et al. uniformen Nanoporen. PhD thesis, Ulm University, Ulm, Germany (in German).

22. Zahid OK and Hall AR (2016) Helium ion microscope fabrication of solid-state nanopore devices for biomolecule analysis. In Helium Ion Microscopy (Hlawacek G and Gölzhäuser A (eds)). Springer, Cham, Switzerland, pp. 447-470.

23. Dickmeis C, Altintoprak K, van Rijn P, Wege C and Commandeur U (2018) Bioinspired silica mineralization on viral templates. In Virusderived Nanoparticles for Advanced Technologies (Wege C and Lomonossoff GP (eds)). Springer, Heidelberg, Germany, pp. 337-362.

24. Mireles M and Gaborski TR (2017) Fabrication techniques enabling ultrathin nanostructured membranes for separations. Electrophoresis 38(19): 2374-2388.

25. Wang L, Boutilier MSH, Kidambi PR et al. (2017) Fundamental transport mechanisms, fabrication and potential applications of nanoporous atomically thin membranes. Nature Nanotechnology 12(6): 509-522.

26. Spatz JP, Mößmer S, Möller M et al. (1998) Functional nanostructures by organized macromolecular-metallic hybrid systems. Journal of Luminescence 76-77: 168-173.

27. Segalman RA, Hexemer A, Hayward RC and Kramer EJ (2003) Ordering and melting of block copolymer spherical domains in 2 and 3 dimensions. Macromolecules 36(9): 3272-3288.

28. Kästle G, Boyen HG, Weigl F et al. (2003) Micellar nanoreactors preparation and characterization of hexagonally ordered arrays of metallic nanodots. Advanced Functional Materials 13(11): 853-861.

29. Sabrina B, Oliver D, Sebastian F et al. (2006) An approach for the fabrication of hexagonally ordered arrays of cylindrical nanoholes in crystalline and amorphous silicon based on the self-organization of polymer micelles. Nanotechnology 17(19): 4991.

30. Deng T, Li MW, Wang YF and Liu ZW (2015) Development of solidstate nanopore fabrication technologies. Science Bulletin 60(3): 304-319.

31. Chih Jen L, Thomas A and Alexey B (2006) Fabrication of symmetric sub-5 $\mathrm{nm}$ nanopores using focused ion and electron beams. Nanotechnology 17(13): 3264.

32. Morin A, Lucot D, Ouerghi A et al. (2012) FIB carving of nanopores into suspended graphene films. Microelectronic Engineering 97: 311-316.

33. Biance AL, Gierak J, Bourhis É et al. (2006) Focused ion beam sculpted membranes for nanoscience tooling. Microelectronic Engineering 83(4): 1474-1477.

34. Zhang $H$, Tian $Y$ and Jiang $L$ (2016) Fundamental studies and practical applications of bio-inspired smart solid-state nanopores and nanochannels. Nano Today 11(1): 61-81.

35. Feng Y, Zhang Y, Ying C, Wang D and Du C (2015) Nanopore-based fourth-generation DNA sequencing technology. Genomics, Proteomics \& Bioinformatics 13(1): 4-16.

36. Chang $H$, Iqbal SM, Stach EA et al. (2006) Fabrication and characterization of solid-state nanopores using a field emission scanning electron microscope. Applied Physics Letters 88(10): 103109.

37. Wu MY, Krapf D, Zandbergen M, Zandbergen $H$ and Batson PE (2005) Formation of nanopores in a $\mathrm{SiN} / \mathrm{SiO}_{2}$ membrane with an electron beam. Applied Physics Letters 87(11): 113106.

38. Storm AJ, Chen JH, Ling XS, Zandbergen HW and Dekker C (2003) Fabrication of solid-state nanopores with single-nanometre precision. Nature Materials 2(8): 537-540.

39. Garaj S, Hubbard W, Reina A et al. (2010) Graphene as a subnanometre trans-electrode membrane. Nature 467(7312): 190-193.

40. Merchant CA, Healy K, Wanunu M et al. (2010) DNA translocation through graphene nanopores. Nano Letters 10(8): 2915-2921.

41. Li J, Stein D, McMullan C et al. (2001) Ion-beam sculpting at nanometre length scales. Nature 412(6843): 166-169.
42. Gierak J, Madouri A, Biance AL et al. (2007) Sub-5nm FIB direct patterning of nanodevices. Microelectronic Engineering 84(5): 779-783.

43. Yang J, Ferranti DC, Stern LA et al. (2011) Rapid and precise scanning helium ion microscope milling of solid-state nanopores for biomolecule detection. Nanotechnology 22(28): 285310.

44. Marshall MM, Yang J and Hall AR (2012) Direct and transmission milling of suspended silicon nitride membranes with a focused helium ion beam. Scanning 34(2): 101-106.

45. Kohli P, Wirtz M and Martin CR (2004) Nanotube membrane based biosensors. Electroanalysis 16(1-2): 9-18.

46. Dekker C (2007) Solid-state nanopores. Nature Nanotechnology 2(4): 209-215

47. Hall AR, Scott A, Rotem D et al. (2010) Hybrid pore formation by directed insertion of $\alpha$-haemolysin into solid-state nanopores. Nature Nanotechnology 5(12): 874-877.

48. Boutilier MSH, Jang D, Idrobo JC et al. (2017) Molecular sieving across centimeter-scale single-layer nanoporous graphene membranes. ACS Nano 11(6): 5726-5736.

49. van den Berg A and Wessling M (2007) Nanofluidics: silicon for the perfect membrane. Nature 445(7129): 726.

50. Striemer CC, Gaborski TR, McGrath JL and Fauchet PM (2007) Charge- and size-based separation of macromolecules using ultrathin silicon membranes. Nature 445(7129): 749-753.

51. Prabhu AS, Jubery TZN, Freedman KJ et al. (2010) Chemically modified solid state nanopores for high throughput nanoparticle separation. Journal of Physics: Condensed Matter 22(45): 454107.

52. Albrecht T, Edel JB and Winterhalter M (2010) New developments in nanopore research - from fundamentals to applications. Journal of Physics: Condensed Matter 22(45): 450301.

53. Willmott GR, Vogel R, Yu SSC et al. (2010) Use of tunable nanopore blockade rates to investigate colloidal dispersions. Journal of Physics: Condensed Matter 22(45): 454116.

54. Niedringhaus TP, Milanova D, Kerby MB, Snyder MP and Barron AE (2011) Landscape of next-generation sequencing technologies. Analytical Chemistry 83(12): 4327-4341.

55. Liu L, Li Y, Li S et al. (2012) Comparison of next-generation sequencing systems. Journal of Biomedicine \& Biotechnology 2012: 251364.

56. Powell MR, Sullivan M, Vlassiouk I et al. (2007) Nanoprecipitationassisted ion current oscillations. Nature Nanotechnology 3(1): 51-57.

57. Daiguji H (2010) Ion transport in nanofluidic channels. Chemical Society Reviews 39(3): 901-911.

58. Joseph WFR, John JK and Joseph ER (2010) Changes in ion channel geometry resolved to sub-ångström precision via single molecule mass spectrometry. Journal of Physics: Condensed Matter 22(45): 454108.

59. Hille B (1992) Ionic Channels of Excitable Membranes, 2nd edn. Sinauer Associates, Sunderland, MA, USA.

60. Jackson MB (2006) Molecular and Cellular Biophysics. Cambridge University Press, Cambridge, UK.

61. Nishizawa M, Menon VP and Martin CR (1995) Metal nanotubule membranes with electrochemically switchable ion-transport selectivity. Science 268(5211): 700-702.

62. Kohli P, Harrell CC, Cao Z et al. (2004) DNA-functionalized nanotube membranes with single-base mismatch selectivity. Science 305(5686): 984-986.

63. Wolfram MT, Burger M and Siwy ZS (2010) Mathematical modeling and simulation of nanopore blocking by precipitation. Journal of Physics: Condensed Matter 22(45): 454101.

64. Mikiembo K and Stefan H (2010) Electrically sensing protease activity with nanopores. Journal of Physics: Condensed Matter 22(45): 454103.

65. Howorka S and Siwy Z (2009) Nanopore analytics: sensing of single molecules. Chemical Society Reviews 38(8): 2360-2384. 
Bioinspired, Biomimetic and Nanobiomaterials Volume 8 Issue BBN1
Improved manufacture of hybrid membranes with bionanopore adapters capable of self-luting Altintoprak, Farajollahi, Seidenstücker et al.
66. Vlassiouk I, Smirnov S and Siwy Z (2008) Ionic selectivity of single nanochannels. Nano Letters 8(7): 1978-1985.

67. Plecis A, Schoch RB and Renaud P (2005) Ionic transport phenomena in nanofluidics: experimental and theoretical study of the exclusionenrichment effect on a chip. Nano Letters 5(6): 1147-1155.

68. Siwy ZS and Howorka S (2010) Engineered voltage-responsive nanopores. Chemical Society Reviews 39(3): 1115-1132.

69. White HS and Bund A (2008) Mechanism of electrostatic gating at conical glass nanopore electrodes. Langmuir 24(20): 12062-12067.

70. Umehara S, Pourmand N, Webb CD et al. (2006) Current rectification with poly-1-lysine-coated quartz nanopipettes. Nano Letters 6(11): 2486-2492.

71. Wei C, Bard AJ and Feldberg SW (1997) Current rectification at quartz nanopipet electrodes. Analytical Chemistry 69(22): 4627-4633.

72. Apel PY, Korchev YE, Siwy Z, Spohr R and Yoshida M (2001) Diodelike single-ion track membrane prepared by electro-stopping. Nuclear Instruments and Methods in Physics Research Section B Beam Interactions with Materials and Atoms 184(3): 337-346.

73. Vlassiouk I and Siwy ZS (2007) Nanofluidic diode. Nano Letters 7(3): 552-556.

74. Cheng LJ and Guo LJ (2009) Ionic current rectification, breakdown, and switching in heterogeneous oxide nanofluidic devices. $A C S$ Nano 3(3): 575-584.

75. Cervera J, Schiedt B and Ramírez P (2005) A Poisson/Nernst-Planck model for ionic transport through synthetic conical nanopores. EPL - Europhysics Letters 71(1): 35.

76. Kirkham J, Firth A, Vernals D et al. (2007) Self-assembling peptide scaffolds promote enamel remineralization. Journal of Dental Research 86(5): 426-430.

77. Semino CE (2008) Self-assembling peptides: from bio-inspired materials to bone regeneration. Journal of Dental Research 87(7): 606-616.

78. Martins-Junior PA, Alcantara CE, Resende RR and Ferreira AJ (2013) Carbon nanotubes: directions and perspectives in oral regenerative medicine. Journal of Dental Research 92(7): 575-583.

79. Tenenbaum HC and Heersche JN (1982) Differentiation of osteoblasts and formation of mineralized bone in vitro. Calcified Tissue International 34(1): 76-79.

80. Bhattacharya $\mathrm{M}$, Wutticharoenmongkol-Thitiwongsawet $\mathrm{P}$, Hamamoto DT et al. (2011) Bone formation on carbon nanotube composite. Journal of Biomedical Materials Research, Part A 96(1): 75-82.

81. Chung WJ, Kwon KY, Song J and Lee SW (2011) Evolutionary screening of collagen-like peptides that nucleate hydroxyapatite crystals. Langmuir 27(12): 7620-7628.

82. Coffman EA, Melechko AV, Allison DP, Simpson ML and Doktycz MJ (2004) Surface patterning of silica nanostructures using bio-inspired templates and directed synthesis. Langmuir 20(20): 8431-8436.

83. Lee WJ, Lee DH, Han TH et al. (2011) Biomimetic mineralization of vertical N-doped carbon nanotubes. Chemical Communications (Cambridge, United Kingdom) 47(1): 535-537.

84. Gorain B, Tekade M, Kesharwani P et al. (2017) The use of nanoscaffolds and dendrimers in tissue engineering. Drug Discovery Today 22(4): 652-664.

85. Yamashita I (2008) Biosupramolecules for nano-devices: biomineralization of nanoparticles and their applications. Journal of Materials Chemistry 18(32): 3813-3820.

86. Tang F, Li L and Chen D (2012) Mesoporous silica nanoparticles: synthesis, biocompatibility and drug delivery. Advanced Materials 24(12): 1504-1534

87. van der Zwaag S, van Dijk NH, Jonkers HM, Mookhoek SD and Sloof WG (2009) Self-healing behaviour in man-made engineering materials: bioinspired but taking into account their intrinsic character. Philosophical Transactions of the Royal Society, A: Mathematical, Physical \& Engineering Sciences 367(1894): 1689-1704.
88. Krajina BA, Proctor AC, Schoen AP, Spakowitz AJ and Heilshorn SC (2018) Biotemplated synthesis of inorganic materials: an emerging paradigm for nanomaterial synthesis inspired by nature. Progress in Materials Science 91: 1-23.

89. Thota V and Perry CC (2017) A review on recent patents and applications of inorganic material binding peptides. Recent Patents on Nanotechnology 11(3): 168-180.

90. Aljabali AAA, Shah SN, Evans-Gowing R, Lomonossoff GP and Evans DJ (2011) Chemically-coupled-peptide-promoted virus nanoparticle templated mineralization. Integrative Biology 3(2): 119-125.

91. Yang W, Guo W, Chang J and Zhang B (2017) Protein/peptidetemplated biomimetic synthesis of inorganic nanoparticles for biomedical applications. Journal of Materials Chemistry B 5(3): 401-417.

92. Care A, Bergquist PL and Sunna A (2017) Solid-binding peptides in biomedicine. In Peptides and Peptide-based Biomaterials and their Biomedical Applications (Sunna A, Care A and Bergquist PL (eds)). Springer, Cham, Switzerland, pp. 21-36.

93. Kröger N (2007) Prescribing diatom morphology: toward genetic engineering of biological nanomaterials. Current Opinion in Chemical Biology 11(6): 662-669.

94. Cha JN, Shimizu K, Zhou Y et al. (1999) Silicatein filaments and subunits from a marine sponge direct the polymerization of silica and silicones in vitro. Proceedings of the National Academy of Sciences of the United States of America 96(2): 361-365.

95. Kröger N, Deutzmann R and Sumper M (1999) Polycationic peptides from diatom biosilica that direct silica nanosphere formation. Science 286(5442): 1129-1132.

96. Baio JE, Zane A, Jaeger V et al. (2014) Diatom mimics: directing the formation of biosilica nanoparticles by controlled folding of lysineleucine peptides. Journal of the American Chemical Society 136(43): 15134-15127.

97. Zane AC, Michelet C, Roehrich A, Emani PS and Drobny GP (2014) Silica morphogenesis by lysine-leucine peptides with hydrophobic periodicity. Langmuir 30(24): 7152-7161.

98. Kuno T, Nonoyama T, Hirao K and Kato K (2011) Influence of the charge relay effect on the silanol condensation reaction as a model for silica biomineralization. Langmuir 27(21): $13154-13158$.

99. Lechner CC and Becker CF (2013) Modified silaffin R5 peptides enable encapsulation and release of cargo molecules from biomimetic silica particles. Bioorganic \& Medicinal Chemistry 21(12): 3533-3541.

100. Yildirim A, Acar H, Erkal TS, Bayindir M and Guler MO (2011) Template-directed synthesis of silica nanotubes for explosive detection. ACS Applied Materials \& Interfaces 3(10): 4159-4164.

101. Kisailus D, Najarian M, Weaver JC and Morse DE (2005) Functionalized gold nanoparticles mimic catalytic activity of a polysiloxane-synthesizing enzyme. Advanced Materials 17(10): 1234-1239.

102. Kisailus D, Truong Q, Amemiya Y, Weaver JC and Morse DE (2006) Self-assembled bifunctional surface mimics an enzymatic and templating protein for the synthesis of a metal oxide semiconductor. Proceedings of the National Academy of Sciences of the United States of America 103(15): 5652-5657.

103. Polini A, Pagliara S, Camposeo A et al. (2012) Optical properties of in-vitro biomineralised silica. Scientific Reports 2: 607.

104. Kotzsch A, Pawolski D, Milentyev A et al. (2016) Biochemical composition and assembly of biosilica-associated insoluble organic matrices from the diatom Thalassiosira pseudonana. Journal of Biological Chemistry 291(10): 4982-4997.

105. Poulsen N and Kröger N (2004) Silica morphogenesis by alternative processing of silaffins in the diatom Thalassiosira pseudonana. Journal of Biological Chemistry 279(41): 42993-42999. 
Bioinspired, Biomimetic and Nanobiomaterials Volume 8 Issue BBN1
Improved manufacture of hybrid membranes with bionanopore adapters capable of self-luting

Altintoprak, Farajollahi, Seidenstücker et al.
106. Sumper $M$ and Brunner E (2008) Silica biomineralization in diatoms: the model organism Thalassiosira pseudonana. ChemBioChem 9(8): 1187-1194.

107. Schröder HC, Wiens M, Schlossmacher U, Brandt D and Müller WEG (2012) Silicatein-mediated polycondensation of orthosilicic acid: modeling of a catalytic mechanism involving ring formation. Silicon 4(1): 33-38.

108. Weaver JC and Morse DE (2003) Molecular biology of demosponge axial filaments and their roles in biosilicification. Microscopy Research and Technique 62(4): 356-367.

109. Belton DJ, Deschaume O, Patwardhan SV and Perry CC (2010) A solution study of silica condensation and speciation with relevance to in vitro investigations of biosilicification. Journal of Physical Chemistry B 114(31): 9947-9955.

110. Belton DJ, Deschaume O and Perry CC (2012) An overview of the fundamentals of the chemistry of silica with relevance to biosilicification and technological advances. FEBS Journal 279(10): 1710-1720.

111. Lee SY, Lim JS, Culver JN and Harris MT (2008) Coagulation of tobacco mosaic virus in alcohol-water- $\mathrm{LiCl}$ solutions. Journal of Colloid and Interface Science 324(1-2): 92-98.

112. Gebauer D, Kellermeier M, Gale JD, Bergström $L$ and Cölfen $H$ (2014) Pre-nucleation clusters as solute precursors in crystallisation. Chemical Society Reviews 43(7): 2348-2371.

113. Icopini GA, Brantley SL and Heaney PJ (2005) Kinetics of silica oligomerization and nanocolloid formation as a function of $\mathrm{pH}$ and ionic strength at $25^{\circ} \mathrm{C}$. Geochimica et Cosmochimica Acta 69(2): 293-303.

114. Butler PJ (1999) Self-assembly of tobacco mosaic virus: the role of an intermediate aggregate in generating both specificity and speed. Philosophical Transactions of the Royal Society B 354(1383): 537-550.

115. Zaitlin $M$ and Palukaitis P (2000) Advances in understanding plant viruses and virus diseases. Annual Review of Phytopathology 38: 117-143.

116. Fraenkel-Conrat $\mathrm{H}$ and Williams RC (1955) Reconstitution of active tobacco mosaic virus from its inactive protein and nucleic acid components. Proceedings of the National Academy of Sciences of the United States of America 41(10): 690-698.

117. Turner DR, Joyce LE and Butler PJ (1988) The tobacco mosaic virus assembly origin RNA: functional characteristics defined by directed mutagenesis. Journal of Molecular Biology 203(3): 531-547.

118. Rego JM, Lee JH, Lee DH and Yi H (2013) Biologically inspired strategy for programmed assembly of viral building blocks with controlled dimensions. Biotechnology Journal 8(2): 237-246.

119. Eber FJ, Eiben S, Jeske H and Wege C (2013) Bottom-up-assembled nanostar colloids of gold cores and tubes derived from tobacco mosaic virus. Angewandte Chemie, International Edition 52(28): 7203-7207.

120. Müller A, Eber FJ, Azucena C et al. (2011) Inducible site-selective bottom-up assembly of virus-derived nanotube arrays on RNAequipped wafers. ACS Nano 5(6): 4512-4520.

121. Wu Z, Müller A, Degenhard S et al. (2010) Enhancing the magnetoviscosity of ferrofluids by the addition of biological nanotubes. ACS Nano 4(8): 4531-4538.

122. Shukla S, Eber F, Nagarajan AS et al. (2015) The impact of aspect ratio on biodistribution and tumor homing of rigid soft-matter nanorods. Advanced Healthcare Materials 4(6): 874-882.

123. Wenz N, Piasecka S, Kalinowski M et al. (2018) Building expanded structures from tetrahedral DNA branching elements, RNA and TMV protein. Nanoscale 2018(10): 6496-6510.

124. Eber FJ, Eiben S, Jeske $\mathrm{H}$ and Wege C (2015) RNA-controlled assembly of tobacco mosaic virus-derived complex structures: from nanoboomerangs to tetrapods. Nanoscale 7(1): 344-355

125. Lomonossoff GP and Wege C (2018) TMV particles: the journey from fundamental studies to bionanotechnology applications. Advances in Virus Research (Kielian M, Mettenleiter T and
Roossinck M (eds)). Elsevier, Amsterdam, the Netherlands, vol. 102, in press.

126. Durham AC, Finch JT and Klug A (1971) States of aggregation of tobacco mosaic virus protein. Nature (London), New Biology 229(2): 37-42.

127. Durham AC and Klug A (1971) Polymerization of tobacco mosaic virus protein and its control. Nature (London), New Biology 229(2): $42-46$.

128. Zhou K, Li F, Dai G, Meng C and Wang Q (2013) Disulfide bond: dramatically enhanced assembly capability and structural stability of tobacco mosaic virus nanorods. Biomacromolecules 14(8): 2593-2600.

129. Butler PJ, Bloomer AC and Finch JT (1992) Direct visualization of the structure of the ' $20 \mathrm{~S}$ ' aggregate of coat protein of tobacco mosaic virus: the 'disk' is the major structure at $\mathrm{pH} 7.0$ and the proto-helix at lower pH. Journal of Molecular Biology 224(2): 381-394.

130. Miller RA, Presley AD and Francis MB (2007) Self-assembling lightharvesting systems from synthetically modified tobacco mosaic virus coat proteins. Journal of the American Chemical Society 129(11): 3104-3109.

131. Finbloom JA, Han K, Aanei IL et al. (2016) Stable disk assemblies of a tobacco mosaic virus mutant as nanoscale scaffolds for applications in drug delivery. Bioconjugate Chemistry 27(10): 2480-2485.

132. Schlick TL, Ding Z, Kovacs EW and Francis MB (2005) Dual-surface modification of the tobacco mosaic virus. Journal of the American Chemical Society 127(11): 3718-3723.

133. Jung S and Yi H (2014) An integrated approach for enhanced protein conjugation and capture with viral nanotemplates and hydrogel microparticle platforms via rapid bioorthogonal reactions. Langmuir 30(26): 7762-7770.

134. Ma YZ, Miller RA, Fleming GR and Francis MB (2008) Energy transfer dynamics in light-harvesting assemblies templated by the tobacco mosaic virus coat protein. Journal of Physical Chemistry B 112(22): 6887-6892.

135. Lee SY, Royston E, Culver JN and Harris MT (2005) Improved metal cluster deposition on a genetically engineered tobacco mosaic virus template. Nanotechnology 16(7): S435-S441.

136. Zaitlin M and Israel H (1975) Tobacco Mosaic Virus (Type Strain). Association of Applied Biology, Wellesbourne, UK, CMI/AAB Descriptions of Plant Viruses No. 151.

137. Taton TA (2002) Preparation of gold nanoparticle-DNA conjugates. Current Protocols in Nucleic Acid Chemistry 9(1): 12.12.11-12.12.12.

138. Pouget E and Grelet E (2013) Dispersions of monodisperse hybrid rod-like particles by mineralization of filamentous viruses. Langmuir 29(25): 8010-8016.

139. Haase NR, Shian S, Sandhage KH and Kröger N (2011) Biocatalytic nanoscale coatings through biomimetic layer-by-layer mineralization. Advanced Functional Materials 21(22): 4243-4251.

140. Green MR and Sambrook J (2012) Molecular Cloning: a Laboratory Manual. Cold Spring Harbor Laboratory Press, New York, NY, USA.

141. Gooding GV Jr and Hebert TT (1967) A simple technique for purification of tobacco mosaic virus in large quantities. Phytopathology 57(11): 1285.

142. Laemmli UK (1970) Cleavage of structural proteins during the assembly of the head of bacteriophage T4. Nature 227(5259): 680-685.

143. Kadri A, Wege C and Jeske H (2013) In vivo self-assembly of TMVlike particles in yeast and bacteria for nanotechnological applications. Journal of Virological Methods 189(2): 328-340.

144. Zimmern D (1983) An extended secondary structure model for the TMV assembly origin, and its correlation with protection studies and an assembly defective mutant. EMBO Journal 2(11): 1901-1907.

145. Fraenkel-Conrat H (1957) Degradation of tobacco mosaic virus with acetic acid. Virology 4(1): 1-4.

146. Gaddipati JP, Atreya CD, Rochon D and Siegel A (1988) Characterization of the TMV encapsidation initiation site on $18 \mathrm{~S}$ rRNA. Nucleic Acids Research 16(15): 7303-7313. 
Bioinspired, Biomimetic and Nanobiomaterials Volume 8 Issue BBN1
Improved manufacture of hybrid membranes with bionanopore adapters capable of self-luting Altintoprak, Farajollahi, Seidenstücker et al.
147. Blevins T (2010) Northern blotting techniques for small RNAs. In Plant Epigenetics - Methods and Protocols (Kovalchuk I and Zemp FJ (eds)). Springer, Heidelberg, Germany, pp. 87-107.

148. Pall GS and Hamilton AJ (2008) Improved northern blot method for enhanced detection of small RNA. Nature Protocols 3(6): 1077-1084

149. Tuma RS, Beaudet MP, Jin X et al. (1999) Characterization of SYBR Gold nucleic acid gel stain: a dye optimized for use with 300-nm ultraviolet transilluminators. Analytical Biochemistry 268(2): 278-288

150. Paul HL (1958) Spektralphotometrische Untersuchungen am Tabakmosaik-Virus. Archiv für Mikrobiologie 30(3): 304-317 (in German).

151. Häkkinen H (2012) The gold-sulfur interface at the nanoscale Nature Chemistry 4(6): 443-455.

152. Bernards TNM, Vanbommel MJ and Boonstra AH (1991) Hydrolysis - condensation processes of the tetra-alkoxysilanes TPOS, TEOS and TMOS in some alcoholic solvents. Journal of Non-crystalline Solids 134(1-2): 1-13

153. Shimada K and Tarutani T (1979) Gel chromatographic study of the polymerization of silicic acid. Journal of Chromatography A 168(2): 401-406.

154. Krauskopf KB (1956) Dissolution and precipitation of silica at low temperatures. Geochimica et Cosmochimica Acta 10(1): 1-26.

155. Shenton W, Douglas T, Young M, Stubbs G and Mann S (1999) Inorganic-organic nanotube composites from template mineralization of tobacco mosaic virus. Advanced Materials 11(3): 253-256.

156. Lu B, Stubbs G and Culver JN (1996) Carboxylate interactions involved in the disassembly of tobacco mosaic tobamovirus. Virology 225(1): 11-20

157. Paglini S and Lauffer MA (1968) Polymerization-depolymerization of tobacco mosaic virus protein: XI. osmotic pressure studies of solutions in water and in deuterium. Biochemistry 7(5): 1827-1835.

158. Stauffer $H$, Srinivasan $S$ and Lauffer MA (1970) Calorimetric studies on polymerization-depolymerization of tobacco mosaic virus protein Biochemistry 9(2): 193-200

159. Niu Z, Bruckman M, Kotakadi VS et al. (2006) Study and characterization of tobacco mosaic virus head-to-tail assembly assisted by aniline polymerization. Chemical Communications (Cambridge, United Kingdom) 2006(28): 3019-3021.

160. Coradin T and Livage J (2001) Effect of some amino acids and peptides on silicic acid polymerization. Colloids and Surfaces, $B$ Biointerfaces 21(4): 329-336.

161. Putnam C (2015) Protein Calculator v3.4. The Scripps Research Institute, La Jolla, CA, USA. See http://protcalc.sourceforge.net (accessed 14/09/2018).

162. Patwardhan SV, Emami FS, Berry RJ et al. (2012) Chemistry of aqueous silica nanoparticle surfaces and the mechanism of selective peptide adsorption. Journal of the American Chemical Society 134(14): 6244-6256.

163. El Shafei GMS (2000) Silica surface chemical properties. In Adsorption on Silica Surfaces (Papirer E (ed.)). Marcel Dekker, New York, NY, USA, pp. 35-62.

164. Yuwono VM and Hartgerink JD (2007) Peptide amphiphile nanofibers template and catalyze silica nanotube formation. Langmuir 23(9): 5033-5038.

165. Kobayashi M, Seki M, Tabata H, Watanabe $Y$ and Yamashita I (2010) Fabrication of aligned magnetic nanoparticles using tobamoviruses. Nano Letters 10(3): 773-776.

166. Holm L and Laakso LM (2016) Dali server update. Nucleic Acids Research 44(W1): W351-W355.

167. Wittmann-Liebold B and Wittmann HG (1967) Coat proteins of strains of two RNA viruses: comparison of their amino acid sequences. Molecular and General Genetics 100(4): 358-363.

168. Wilson TM, Perham RN, Finch JT and Butler PJ (1976) Polarity of the RNA in the tobacco mosaic virus particle and the direction of protein stripping in sodium dodecyl sulphate. FEBS Letters 64(2): 285-289.

169. Balci S, Noda K, Bittner AM et al. (2007) Self-assembly of metalvirus nanodumbbells. Angewandte Chemie, International Edition 46(17): 3149-3151.

170. Stubbs G, Warren S and Holmes K (1977) Structure of RNA and RNA binding site in tobacco mosaic virus from 4-Å map calculated from X-ray fibre diagrams. Nature 267(5608): 216-221.

\section{How can you contribute?}

To discuss this paper, please submit up to 500 words to the journal office at journals@ice.org.uk. Your contribution will be forwarded to the author(s) for a reply and, if considered appropriate by the editor-in-chief, it will be published as a discussion in a future issue of the journal.

ICE Science journals rely entirely on contributions from the field of materials science and engineering. Information about how to submit your paper online is available at www.icevirtuallibrary.com/page/authors, where you will also find detailed author guidelines. 